Federal Reserve Bank of Minneapolis

Research Department

\title{
Moral Hazard Under Commercial and Universal Banking
}

John H. Boyd, Chun Chang, and Bruce D. Smith*

Working Paper 585D

Revised January 1998

\begin{abstract}
Many claims have been made about the potential benefits, and the potential costs, of adopting a system of universal banking in the United States. We evaluate these claims using a model where there is a moral hazard problem between banks and "borrowers," a moral hazard problem between banks and a deposit insurer, and a costly state verification problem. Under conditions we describe, allowing banks to take equity positions in firms strengthens their ability to extract surplus, and exacerbates problems of moral hazard. The incentives of universal banks to take equity positions will often be strongest when these problems are most severe.
\end{abstract}


*John H. Boyd is a professor of finance in the Carlson School of Management at the University of Minnesota and an adjunct consultant with the Federal Reserve Bank of Minneapolis; Chun Chang is an associate professor of finance in the Carlson School of Management at the University of Minnesota; and Bruce D. Smith is a professor of economics at the University of Texas at Austin. We have benefitted from the helpful comments of Doug Diamond, Joe Haubrich, Ross Levine, Stan Longhofer, Jaoa Santos, and an anonymous referee. The views expressed herein are those of the authors and not necessarily those of the Federal Reserve Bank of Minneapolis or the Federal Reserve System. 


\section{Introduction}

For many decades, commercial banks in the United States have been prohibited from making equity investments in the firms they serve. Rather, they are restricted to providing them with loans in the form, essentially, of debt contracts. This longstanding regulatory restriction ${ }^{1}$ results in distinctly different roles for bank lenders and equity investors, and has had important implications for the entire financial sector.

The American system of "commercial banking" presents a sharp contrast with the banking systems of some other countries, most notably Germany, in which banks are permitted to take equity positions. Under such "universal banking" arrangements, banks can make equity investments as well as loans, vote their equity shares, and even hold seats on the boards of directors of nonfinancial firms. In general, they can be actively involved in all aspects of firm decision-making. In Germany, the control rights of owner-banks are further enhanced by the fact that they can vote the shares of other agents which they hold in trust (auftragsstimmrecht). ${ }^{2}$

These important differences in banking arrangements have not escaped the notice of scholars and there is a large literature, both theoretical and empirical, that compares the two types of banking systems. Indeed, many academics_as well as policymakers—-have proposed that the United States adopt a form of universal banking and this issue is under active, ongoing debate in the Congress. ${ }^{3}$ The obvious point is that this subject is of significant public policy concern, as well as of academic interest.

A second issue that looms very large in discussions of banking and bank regulation is the control of moral hazard problems. Moral hazard in banking can clearly take either or both of two forms. Moral hazard problems can easily arise in the relationship between banks and the agents to whom they provide funds. In addition, it has long been recognized that the presence of deposit insurance gives rise to a moral hazard problem between banks and the providers of deposit insurance 
(the FDIC). [See, for instance, Kareken and Wallace (1978) and Merton (1978).] And indeed, regulators have often expressed the concern that the establishment of universal banking in the U.S. could extend the "governmental safety net" far too broadly, that moral hazard problems could be exacerbated as a consequence, and that they could, potentially, be transmitted beyond the financial sector. [See, for example, Corrigan $(1983,1987)$ or Saunders (1994).]

In this paper we investigate the severity of both kinds of moral hazard problems under both commercial and universal banking. In particular, we investigate optimal bank behavior under each regime, and then pose the following two questions: (i) how severe is the moral hazard problem between banks and "borrowers;" and (ii) how severe is the moral hazard problem between banks and the FDIC?

We begin by studying a system of commercial banking where banks are precluded from taking equity positions in the firms to which they lend. We show that under commercial banking, banks will always take some actions to control the moral hazard problem between borrowers and themselves. These actions also tend to limit the implied obligations of the FDIC, since the active control of moral hazard problems by banks implies that banks fail less often and, on average, have assets of greater value when they do fail.

We then contrast this with a banking system (universal banking) where banks take equity positions in the firms they serve. ${ }^{4}$ When banks are allowed to take equity positions, and to assume some control rights, their incentives to control moral hazard problems can be substantially attenuated. Indeed, under universal banking banks can share more easily in the benefits of "misallocating" funds, and they can more easily pass losses onto the FDIC. This exacerbates problems of moral hazard along both dimensions. Moreover, by exercising their control rights, banks can force firms to "misallocate" funds even when this is beneficial neither to the firm nor to society (although clearly it is beneficial to the bank). This alteration in the allocation of funds also has adverse consequences 
for the FDIC. Finally, we identify some economic factors that are conducive to problems of moral hazard being particularly severe under universal banking. These factors include: (i) low real returns on savings, (ii) a relatively high return to misallocated funds, (iii) a high cost to banks associated with deterring moral hazard, and (iv) banks obtaining relatively large equity positions under universal banking.

Having analyzed these issues we then ask a third question: When will a bank, if given a choice between a debt and an equity claim, choose to take an equity position in a firm? Loosely speaking, we find that banks prefer equity claims when: (i) the return to misallocating funds is relatively high, and hence the moral hazard problem is relatively severe, (ii) their probability of failure as a commercial bank is relatively high (it will then be even higher under universal banking, again reflecting greater moral hazard), (iii) ex post state verification costs are relatively low, and (iv) the bank is able to obtain a relatively large equity position under universal banking. (The latter factor again is associated with moral hazard problems being more severe under universal banking).

Finally, we show that the two types of banking systems have sharply differing general equilibrium implications for resource allocations. In particular, under universal banking a larger portion of the surplus generated by externally financed investment accrues to banks, and less accrues to the originating investor. This clearly can have far-reaching implications for aggregate investment activity. In addition, problems of moral hazard in investment will often, as we have noted, be of greater concern under universal than under commercial banking. Together, these observations suggest that universal banking can easily have adverse consequences for the overall efficiency of investment.

Our vehicle for addressing the issues just described is a model in which all deposits are fully insured by the FDIC. Such insurance is socially valuable in our framework because, by assumption, banks are unable to perfectly diversify risk and most depositor-savers are risk-averse. Further, all savings and investment is intermediated through banks. The FDIC charges a fixed-rate insurance 
premium to banks, ${ }^{5}$ and, in addition, the FDIC has recourse to taxation of savers whenever necessary to meet its insurance liabilities. Symmetrically, any excess insurance receipts are returned to savers. Besides banks, the FDIC and savers, a fourth class of agents rounds out the model economy. These are "entrepreneurs" who are endowed with access to productive investment technologies which require external financing.

There are three possible sources of moral hazard in our model. Two of these arise endogenously, and one arises exogenously through the provision of deposit insurance. The first endogenous source of moral hazard takes the form of a standard costly state verification (CSV) problem: only the "entrepreneurs" can freely observe the return realizations on their investment projects. All other agents must employ a costly monitoring technology to observe project returns. The second endogenous source of moral hazard is that project owners can, prior to investment, divert funds, consuming them in the form of perquisites and the like. Specifically, in the model environment investment projects come in two different sizes, large and small. Project owners can claim to be undertaking the large investment—while actually doing the smaller one-and then consume the difference in the form of "perks." This action is unobservable to other agents except by engaging in costly interim monitoring. It is also socially wasteful, in the sense that the utility of perquisites consumption is assumed to be less than the utility of income.

If the bank is an equity holder in the project, and if it agrees to the diversion of funds, the bank then participates in the consumption of perquisites in proportion to its ownership claim. Alternatively, it can block perquisites consumption by engaging in costly interim monitoring. However, if the bank has entered into a debt contract it has the option of blocking perquisites consumption, but cannot itself participate in that activity. This modeling structure is motivated by the difference in control rights afforded to debt and equity holders, and by the observation that in practice universal banks actively exercise these rights. 
Intuitively, then, any individual bank perceives costs and benefits to operating as a universal bank. The most obvious cost associated with taking an equity position is that this entails an excessively large amount of ex post state verification; as is well-known, debt is the contractual form that minimizes the expected costs of monitoring. In addition, universal banking can easily exacerbate problems of moral hazard between a bank and its borrowers. On the other hand, under our assumptions, universal banks obtain some control rights that permit them to share in the benefits of misallocating investment capital. And - in part as a consequence-the ability of a universal bank to extract surplus from borrowers increases relative to that of a commercial bank. In short, then, operating as a universal bank allows the bank to gain at the expense of its borrowers, and at the expense of the deposit insurer.

How does changing the contract between a bank and a "borrower" produce these effects? As we demonstrate, when a bank takes an equity position in a firm, it ceases to have any interest in how the terms of the contract—or the choice of an investment project—affect its expected monitoring costs. Quite the opposite is true under a debt contract. As a result, banks may be willing to try to extract much more "borrower surplus" when they hold an equity position, and they can often do this by allowing a misallocation of funds to occur. And, of course, a universal bank shares in this benefit.

This logic suggests quite correctly that banks will choose to organize as universal banks when their potential private gains from funds diversion are relatively high, and when their ability to extract surplus from borrowers is relatively great. What we conclude, based on this observation, is that there may well be reason for concern about the incentives created by universal banking. These concerns will typically be exacerbated by the presence of deposit insurance.

Prior to proceeding, it is useful to relate our work to some of the existing literature on universal banking. Boot and Thakor (forthcoming), for instance, examines how alternative banking arrangements affect the incentives for innovation in the financial sector. Berlin, John, and Saunders 
(1996) have studied the role that bank equity investments may play (if permitted), in resolving the problems of financially distressed firms. Santos (1996a) has examined the welfare implications of restrictions on (or prohibition of) bank equity investments in nonfinancial firms. ${ }^{6}$ In addition, there is a large empirical literature that isolates and quantifies performance differences between various banking regimes. [Good examples include Allen and Gale (1995), Hauswald (1996), or Gorton and Schmid (1996). A number of other related studies are discussed by Saunders and Walter (1994).] There is also a large literature examining the provision of investment banking services by universal banks. [See Kroszner and Rajan (1994) or the review by Santos (1996b).] Clearly all of these studies (with the exception of Santos 1996a), have a substantially different focus from ours. Our analysis focuses on the severity of both endogenously arising and policy-induced moral hazard under commercial versus universal banking.

The remainder of the paper proceeds as follows. Section I lays out the model environment, and Section II describes the behavior of agents, and a general equilibrium of the model under commercial banking. Section III considers universal banking, and Section IV discusses when banks will prefer to take equity positions rather than to hold debt claims. Section V offers some concluding remarks.

\section{The Model}

We consider an economy which is populated by a continuum of agents who live for two periods. These agents can be divided into three categories: Borrowers (or entrepreneurs), bankers (or potential bankers), and depositors (savers). In addition, there is a government that operates a deposit insurance system. We now describe each set of agents. 


\section{A. Entrepreneurs}

Borrowers (entrepreneurs) comprise a fraction $\alpha \in(0,1)$ of the population. Each borrower is endowed in period one with access to two investment projects, although at most one of the projects can be operated. A project that is operated in the first period yields a random gross return of $z$, per unit invested, in period 2. For both projects, we assume that $z \in[0, \bar{z}]$.

Projects are differentiated by their scales of operation, and by their probability distributions of returns. Project 1 requires $q_{1}>1$ units of first period resources (funds) to operate. Projects are assumed to be indivisible, so that no project can be operated without a minimum investment, and investments in excess of the minimum are unproductive. If $q_{1}$ units are invested in project 1 , a random return $z$ is realized in the second period, with $\operatorname{prob}(z \leq \tilde{z})=G(\tilde{z})$. We let $g(z)$ denote the pdf of this distribution, and we assume that $g(z)>0$ for all $z \in[0, \bar{z}]$. Finally, let $\hat{z}_{1}$ denote the expected gross return, per unit invested, if project 1 is operated.

Project 2 requires $q_{2}$ units of funds in the first period, with $1 \leq q_{2}<q_{1}$. If project 2 is operated, then $\operatorname{prob}(z \leq \tilde{z})=F(\tilde{z})$, and we assume that

$$
F(z) \geq G(z), \quad \text { for all } z
$$

Thus, the probability distribution of returns on investments in project 1 stochastically dominates that on investments in project 2. We also let $f$ denote the pdf of this distribution, and assume that $f(z)>0$ for all $z \in[0, \bar{z}]$. The mean return-per unit invested-on project 2 is $\hat{z}_{2}$. Clearly $\hat{z}_{2}<\hat{z}_{1}$ holds.

We assume that borrowers can operate either project 1 or project 2. However, only one project can be operated, and we assume that it is infeasible to operate convex combinations of the two projects. Such assumptions are standard in models of moral hazard and costly state verification.

Borrowers are assumed to have no funds-other than those generated by their investment returns - in either period. Thus, to engage in any investment, borrowers must obtain external funding. 
If they fail to do so, we assume that they engage in some outside activity that yields the (exogenously given) utility level $\bar{u} \geq 0$. We also assume that borrowers are risk neutral, so that they will wish to operate any investment project that yields an expected payoff no less than $\bar{u}$.

\section{Information}

We assume that there are two kinds of informational asymmetries associated with the provision of external finance. One is a standard costly state verification problem [Townsend (1979), Diamond (1984), Gale and Hellwig (1985), and Williamson (1986, 1987)]. In particular, for either type of project the random return $z$ can be observed costlessly only by the agent operating the project. For certain other agents the project return can be observed (after the fact) by incurring a fixed cost of $\gamma$ units of effort. Here we allow for the possibility that only some agents can engage in state verification, and that verification costs are not necessarily the same for all individuals who can undertake it. We describe these features of the model in more detail below.

The purpose of introducing costly ex post state verification is to create some presumption that debt contracts are not an inferior contractual form-if we abstract from stochastic monitoring. For this reason, throughout we focus exclusively on ex post monitoring that occurs deterministically. ${ }^{7}$

In addition to the state verification problem, we allow for the presence of a moral hazard problem associated with project choice. In particular, we assume that the borrower's choice of investment project is not observable to the lender ex-ante. Thus, if a borrower receives $q_{1}$ units of funds in period one, he may either invest in project 1 , or he may divert $q_{1}-q_{2}$ and invest in project 2. The diverted funds yield "perks" to owners of the project: we describe these "perks" in more detail below. A borrower who has a second period income of $y$ and who has expended $q_{1}-$ $q_{2}$ units of funds on "perks" receives the lifetime utility $y+\delta\left(q_{1}-q_{2}\right)$. We assume that the preference parameter $\delta$ satisfies $0<\delta \leq 1$, and that $\hat{z}_{2}>\delta .^{8}$ 
While only the borrower knows his own ex ante project choice, we assume that by engaging in what we call interim monitoring, outside lenders can observe that choice at some cost. More specifically, after the project investment has been made (and it is then no longer reversible), a lender can engage in interim monitoring at a cost-in effort- of $\lambda .^{9}$ If this cost is incurred, the lender learns the borrower's project choice. We allow lenders to liquidate the borrower's project at this point: projects of type $j$ have a liquidation value of $L_{j} ; j=1,2$. We also allow interim monitoring to be done stochastically. ${ }^{10}$

Interim monitoring is one device by which a lender can attempt to control the moral hazard problem. We also assume that a second device is available. In particular, we assume that each borrower can deal with only a single lender, and thus that the lender can control the quantity of funds obtained by the borrower. Then, by restricting the quantity of funds extended to $q_{2}$, a lender can always prevent a diversion of funds into "perks." However, whenever $q_{1}>q_{2}$ is lent, a moral hazard problem is always potentially present.

\section{B. Bankers}

A fraction $\beta \in(0,1)$ of the population consists of potential bankers. Each banker is endowed with one unit of funds in the first period, along with some first and second period effort that can be expended on interim and ex post monitoring, respectively. By investing one unit of funds in the first period, a potential banker actuates his ability to engage in both types of monitoring. ${ }^{11}$ And, having expended his own funds, each operating banker must clearly raise some deposits externally.

We assume that investment returns across entrepreneurs are independently distributed. As a consequence, in view of the assumption that there is a large number of agents, there is no aggregate uncertainty in this economy. But, to make deposit insurance valuable, it is clearly necessary to confront the depositors of any bank with some risk that that bank will fail. We accomplish this by 
assuming that any given bank (or banker) has a limited ability to service and monitor loans, and-in particular — can make only a finite number of loans. Given this assumption, complete diversification is impossible for any specific bank. In addition, to keep matters as simple as possible, we restrict each bank to making only a single loan. ${ }^{12}$

We assume that bankers are risk neutral, and that they care only about second period income (consumption) and effort expended on monitoring. Let $y$ denote a banker's second period income, let $e_{I} \in\{0,1\}$ denote effort expenditure on interim monitoring $\left(e_{I}=0\right.$ (1) implies that interim monitoring does not (does) occur), and let $e_{F} \in\{0,1\}$ denote effort expenditure on observing the final project return (again, $e_{F}=0$ (1) indicates that ex post monitoring does not (does) occur). Then the banker's utility is $y-\lambda e_{I}-\gamma e_{F}$. Thus $\lambda(\gamma)$ is the cost of interim (ex post) monitoring.

It will sometimes be interesting to think about there being heterogeneity among banks, with some banks having high and some having low costs of monitoring. Let $\mu(1-\mu)$ denote the fraction of banks that have low (high) monitoring costs. A low (high) cost bank engages in interim monitoring at a utility cost of $\lambda_{L}\left(\lambda_{H}\right)$. A low (high) cost bank engages in ex post state verification at a utility cost of $\gamma_{L}\left(\gamma_{H}\right)$. Clearly we assume that $\lambda_{L} \leq \lambda_{H}$ and $\gamma_{L} \leq \gamma_{H}$, with at least one inequality being strict. When we are not interested in differentiating among high and low cost banks, we will simply set $\mu=0$ or $\mu=1$.

Finally, as the phrase "potential banker" suggests, each potential banker has the option of not running a bank. In this case the potential banker simply saves his single unit of funds, in effect becoming a depositor. And to avoid a potential "shortage of banks," we assume that $\beta \geq \alpha$ holds so that every potential borrower can-at least in principle-find a bank. ${ }^{13}$ 


\section{Depositors}

A fraction $1-\alpha-\beta$ of the population is depositors. Depositors are each endowed with one unit of funds when young, and they care only about second period consumption. Thus, depositors each supply their single unit of funds inelastically in the first period.

We also assume that depositors are risk averse, so that they wish to be insured when old. This insurance is provided through the government (the FDIC), since our "one bank-one borrower" assumption prevents banks from providing this insurance themselves.

\section{Remark}

At this point a brief remark is in order regarding the role for banks in this model. If $q_{2}>1$ holds, then each funded entrepreneur requires more resources than a single saver could provide (even if savers did not have to make an investment in monitoring capacity). Familiar arguments (Diamond 1984 and Williamson 1986) then establish a role for intermediation to avoid the duplication of monitoring costs. Such arguments also apply here even though, under our assumptions, intermediaries are not able to pool risks, as they are in many other models. Risk sharing is described in the next section.

\section{Deposits and Deposit Insurance}

Deposit markets in our model operate as follows. All depositors-as well as potential bankers who opt to become savers-make a deposit with an active bank. Banks offer to pay the gross market rate of return $r$ per unit deposited. Banks who lend to sufficiently successful borrowers will be able to make this payment. However, for banks whose borrowers experience low returns, it will not be feasible to pay $r$ per unit deposited, and the bank will "fail."

The fact that depositors are risk averse implies that they will wish to be insured against bank failures. Moreover, the fact that there is a large number of agents implies that it is feasible for 
society to provide this insurance. We assume that deposit insurance is provided by the government (FDIC). Since one of our primary concerns is with how the provision of deposit insurance by the government affects the incentives of commercial and universal banks to control moral hazard, it is natural for us to assume that deposit insurance is government provided. ${ }^{14}$

The FDIC behaves as follows. For any bank that makes its promised payment of $r$ per unit deposited in period two, the FDIC takes no action. However, when a bank pays less than $r$ per unit deposited the bank fails, and the FDIC liquidates its assets and retains the proceeds. Of course, the FDIC, like other agents, cannot directly observe the return on any bank's assets. Thus, in order to liquidate a bank, the FDIC must engage in costly ex post state verification. For failed banks the FDIC then ascertains the value of the bank's assets, and uses the proceeds to pay off bank depositors. ${ }^{15}$ To conduct ex post state verification the FDIC hires private agents, and we assume that the cost of ex post state verification to the FDIC is $\gamma_{F}{ }^{16}$

Since the FDIC cannot raise enough resources from failed banks to cover the losses experienced by depositors, it must raise some additional resources in other ways. We assume that in period one the FDIC imposes a flat rate deposit insurance premium of $t$ per unit lent on each bank. ${ }^{17}$ The FDIC-like other agents-must then transfer the resources it obtains between periods. To do so, we assume that the FDIC simply deposits its tax income with private banks, and earns the same returns - and is subject to the same risks - as other depositors. This assumption is made because alternate assumptions would result in the revenue raised by the FDIC having an effect on the total supply of savings in period one. In practice, we do not typically think that an important aspect of deposit insurance is how deposit insurance taxes affect the aggregate supply of credit. ${ }^{18}$

Finally, we want to allow for the possibility that the FDIC's revenue from deposit insurance does not necessarily cover its insurance losses. Since FDIC expenditures in period two are perfectly predictable in period one, we assume that the FDIC can levy a lump-sum tax of $\tau$ on all depositors 
(including potential bankers who do not choose to operate banks) in the first period to cover any

shortfall. Again, the proceeds of this tax are deposited with private banks. The value $\tau$ then represents a measure of the losses incurred by the FDIC.

\section{Remarks}

Clearly our intention is to stylistically represent actual government policy as it prevails in the United States. We believe that this is a natural thing to do, since most of the discussion about problems of moral hazard that would be created by moving toward universal banking in the United States presume that the current structure of deposit insurance would continue in place. Of course there is no presumption that these deposit insurance arrangements are in any way optimal.

It is also the case that the FDIC has never had to obtain funding from general tax revenue, but it surely could - and would - if necessary. Indeed, such "tax funding" was actually authorized as recently as the FDICIA Act of 1991 (but then proved unnecessary).

The FDICIA Act also provided for deposit insurance premia determined according to a bank's risk class, as opposed to the simple flat-rate scheme assumed in our analysis. However, the assumption of a flat-rate insurance premium does little violence to reality at the present, as an overwhelming majority of banks are in the same (lowest) risk class. And, of course, until recently all banks were charged the same premium.

A natural question is whether countries that currently allow universal banking have deposit insurance mechanisms in place similar to the one we model? In some cases the answer is yes: Germany provides virtually complete insurance to depositors (Saunders 1997), and Turkey also has a deposit insurance program. In addition, we believe that the reality is that in most countries informal "too big to fail" policies render virtually all depositors insured, irrespective of their formal insurance schemes. For a variety of reasons, including the existence of highly concentrated banking systems 
with a relatively small number of large banks, governments are wont to tolerate bank failures. That reluctance has been quite evident in the recent banking problems in Europe, South America, and Asia.

Finally, the banks in our model have no outside equity holders. Here this is actually optimal, since agents with equity shares in banks would be obligated to duplicate monitoring effort. But this would be an interesting feature of the analysis to modify in future research.

\section{Commercial Banking}

We now analyze the behavior of banks and borrowers-and discuss the determination of a full general equilibrium-under two alternative banking arrangements: commercial banking and universal banking. In this section we exogenously impose a commercial banking structure; by this we mean that banks are restricted to entering into debt contracts with borrowers. In the next section we consider banks that take equity positions in the firms they "lend" to. Then, in Section IV, we comment on when banks that are free to enter into any type of contractual arrangement with borrowers will choose to take equity positions.

The timing of events is as follows. Each potential banker (knowing deposit rates and contract terms) chooses whether to open a bank. Those who do not act as bankers become depositors (deposit their unit of funds with a bank). Those who do act as bankers invest in monitoring capacity.

Once the set of banks is determined, each bank takes deposits and enters into a contractual arrangement (the nature of the contractual arrangement depends on the type of banking system in place) with one borrower. After the contract has been entered into, the borrower makes a choice of which investment project to operate (among those that are feasible given his funding). Subsequent to project choices being made the bank can, if it desires, engage in interim monitoring (which it may do stochastically). At this point the bank can also-if it wants-liquidate the project and call the loan. 
If the loan is not called, the random return $z$ is realized at the beginning of period two. Then payments are made from the borrower to the bank, and verification of the project return is undertaken by the bank as called for by the contract. If it is feasible to do so, the bank then pays $r$ per unit deposited, and pockets any residual. If this is not feasible, the bank is liquidated by the FDIC.

Under commercial banking, banks are restricted to entering into a debt contract with borrowers. Our notion of a debt contract here closely follows the one that is standard in the costly state verification literature (Diamond 1984, Gale and Hellwig 1985, and Williamson 1986, 1987). In particular, a debt contract specifies the following. (a) A probability, denoted $p$, that interim monitoring will be undertaken. (b) A set of ex post verification states, which we denote by $A$. Ex post state verification does not take place if $z \in B=[0, \bar{z}]-A$. (c) A repayment schedule (per unit borrowed) of $R(z)$, for all $z \in A$. (d) An uncontingent payment (that is, a gross rate of interest) $x$ if $z \in B$. Clearly, $B=[x, \bar{z}]$, as in Diamond (1984) and Williamson (1986, 1987). (e) A loan quantity $q$. Here, it clearly suffices to consider $q \in\left\{q_{2}, q_{1}\right\}$.

With these preliminaries, we now proceed to consider the behavior of banks and borrowers under commercial banking.

\section{A. Bank Strategies}

Since a funded borrower can invest only in project 1 or project 2 , any individual bank's strategies are very limited. In this section-as well as Section B-we take the set of active banks, the rate of interest on deposits, and the deposit insurance premium as given. We then investigate the optimal behavior of banks of different kinds. We begin by considering each potential bank strategy in turn. 


\section{Strategy 1}

One strategy that can be undertaken by a bank is as follows. Lend $q_{1}$ to a borrower. It is then feasible for the borrower to undertake either project. To deter the borrower from investing in project 2 and consuming "perks," engage in interim monitoring, and liquidate the investment if the borrower is found to have invested in that project. ${ }^{19}$ Of course under this strategy, the interim monitoring probability $p$ must be set high enough to deter moral hazard.

If a bank follows strategy 1 , we denote the interest rate it charges by $x_{1}$. Then the expected gross return to a bank from following strategy 1, not inclusive of interim monitoring costs (and per unit lent) is given by

$$
x_{1}\left[1-G\left(x_{1}\right)\right]+\int_{0}^{x_{1}} z g(z) d z-\left(\frac{\gamma}{q_{1}}\right) G(x)=x_{1}-\int_{0}^{x_{1}} G(z) d z-\left(\frac{\gamma}{q_{1}}\right) G\left(x_{1}\right) \equiv \pi\left(x_{1}, q_{1} ; \gamma\right)
$$

if its ex post monitoring cost is $\gamma$. The expected return to the borrower from choosing project 1 is

$$
q_{1}\left\{\hat{z}_{1}-x_{1}\left[1-G\left(x_{1}\right)\right]-\int_{0}^{x_{1}} z g(z) d z\right\}=q_{1}\left\{\hat{z}_{1}-x_{1}+\int_{0}^{x_{1}} G(z) d z\right\} .
$$

A crucial question in our analysis is, when is there a moral hazard problem under strategy 1 ? Under commercial banking, and in the absence of interim monitoring, a borrower who receives $q_{1}$ units of funds could invest in project 2 and simultaneously spend $q_{1}-q_{2}$ on "perks." ${ }^{20}$ A borrower following this course of action would "default" on its loan if $q_{2} z<q_{1} x_{1}$. As a result, the expected payoff to the borrower from investing in project 2 is-absent interim monitoring- 


$$
\begin{gathered}
q_{2} \hat{z}_{2}+\delta\left(q_{1}-q_{2}\right)-q_{1} x_{1}\left\{1-F\left[\left(\frac{q_{1}}{q_{2}}\right) x_{1}\right]\right\}-q_{2} \int_{0}^{\left(q_{1} q_{2}\right) x_{1}} z f(z) d z \\
=q_{2} \hat{z}_{2}+\delta\left(q_{1}-q_{2}\right)-q_{1} x_{1}+q_{2} \int_{0}^{\left(q_{1} / q_{2}\right) x_{1}} F(z) d z .
\end{gathered}
$$

Consequently, there is a nontrivial moral hazard problem—under strategy 1 -iff

$$
q_{2} \hat{z}_{2}+\delta\left(q_{1}-q_{2}\right) \geq q_{1} \hat{z}_{1}+q_{1} \int_{0}^{x_{1}} G(z) d z-q_{2} \int_{0}^{\left(q_{1} / q_{2}\right) x_{1}} F(z) d z .
$$

In keeping with our focus on moral hazard problems under different banking arrangements, we henceforth assume that (a.2) holds. ${ }^{21}$ For analytical simplicity we also assume that

$$
\bar{z}>\left(\frac{q_{1}}{q_{2}}\right) x_{1}
$$

Assumption (a.3) simply asserts that when a borrower diverts funds under strategy 1, this does not imply that he defaults on his loan with probability one.

When (a.2) holds, a bank following strategy 1 must engage interim monitoring to deter moral hazard. If the bank engages in interim monitoring and the borrower has diverted funds into expenditures on "perks," we assume that this "perks" consumption occurs before the project can be liquidated; hence the borrower gets $\delta\left(q_{1}-q_{2}\right)$. However, if interim monitoring does not occur, a borrower who diverts funds gets the expected payoff described above. Thus, in order to deter moral hazard, the bank must choose an interim monitoring probability that satisfies the following incentive compatibility constraint: 


$$
q_{1}\left\{\hat{z}_{1}-x_{1}+\int_{0}^{x_{1}} G(z) d z\right\} \geq(1-p)\left\{q_{2} \hat{z}_{2}-q_{1} x_{1}+q_{2} \int_{0}^{\left(q_{1} / q_{2}\right) x_{1}} F(z) d z\right\}+\delta\left(q_{1}-q_{2}\right) .
$$

Since interim monitoring is costly, clearly the bank wants to set $p$ as small as possible. Consequently, the bank's interim monitoring probability is given by ${ }^{22}$

$$
\begin{aligned}
p=\left\{q_{2} \hat{z}_{2}+\delta\left(q_{1}-q_{2}\right)-q_{1} \hat{z}_{1}+q_{2} \int_{0}^{\left(q_{1} / q_{2}\right) x_{1}} F(z) d z\right. \\
\left.\quad-q_{1} \int_{0}^{x_{1}} G(z) d z\right\} /\left\{q_{2} \hat{z}_{2}-q_{1} x_{1}+q_{2} \int_{0}^{\left(q_{1} / q_{2}\right) x_{1}} F(z) d z\right\} \equiv p\left(x_{1}\right) .
\end{aligned}
$$

It is easy to verify that $p^{\prime}\left(x_{1}\right)>0$ holds, so that the probability of interim monitoring must increase (the moral hazard problem becomes more severe) as the interest rate charged under strategy 1 becomes higher. It is also easy to verify that the value of $p$ given by (3) satisfies $p \leq 1$ iff

$$
q_{1} \hat{z}_{1}-\delta\left(q_{1}-q_{2}\right) \geq q_{1} x_{1}-q_{1} \int_{0}^{x_{1}} G(z) d z
$$

holds. Therefore, there is an upper bound on the interest rate that can be charged under strategy 1: interest rates exceeding this bound render it impossible to deter moral hazard. Let $\tilde{x}$ denote the solution to (4) at equality. Then $x_{1} \leq \tilde{x}$ must hold.

Together our observations indicate that the expected payoff to a bank from following strategy 1 , and from charging the interest rate $x_{1}$ is given by (not inclusive of the cost of funds) $q_{1} \pi\left(x_{1}, q_{1} ; \gamma\right)-\lambda p\left(x_{1}\right)$. We now discuss the determination of the interest rate $x_{1}$. 
a. Interest Rate Determination

As is well-known (Williamson 1986,1987$)$, the function $\pi\left(x, q_{1} ; \gamma\right)$ is typically not monotone in $x$. Excessively high rates of interest lead to high probabilities of default, high expected monitoring costs, and low returns to lenders. The probability of interim monitoring is also increasing in $x$. This adds an additional factor leading lenders not to want to charge overly high rates of interest.

When the expected return to a lender is not monotonically increasing in the rate of interest, this opens the possibility that credit can be rationed. In particular, if the supply of funds is low relative to the potential demand for funds, borrowers will compete with each other for scarce loans. But there is a limit to how much they can do so, for if they offer excessively high rates of interest they will make themselves unattractive to lenders.

To simplify our discussion, we henceforth assume that credit is rationed. ${ }^{23}$ This make the determination of loan rates very straightforward; borrowers bid these up to the level that maximizes a lender's expected payoff. Define $\hat{x}_{1}$ by

$$
\hat{x}_{1} \equiv \underset{x \leq \tilde{x}}{\operatorname{argmax}}\left[q_{1} \pi\left(x, q_{1} ; \gamma\right)-\lambda p(x)\right]
$$

Then, under strategy 1 , credit rationing implies that $x_{1}=\hat{x}_{1} \cdot{ }^{24}$

\section{b. The Cost of Funds}

In order to evaluate the net expected payoff to a bank from following strategy 1 , it is necessary to describe the bank's cost of funds under that strategy. A bank following strategy 1 must raise $q_{1}$ units of funds to make its loans, and in addition it must raise $t q_{1}$ units of funds to pay its deposit insurance premiums. Thus, the bank will have deposits equal to $(1+t) q_{1}$. It will be feasible for the bank to pay $r$ on each of these deposits iff its borrower has $z \geq r(1+t)$. Hence, the bank will fail with probability $G[r(1+t)]$. 
If the bank does not fail, it pays $r q_{1}(1+t)$ to depositors. If it does fail, all its assets are liquidated to pay depositors. Let $\Phi_{1}[r(1+t)]$ denote the expected transfer from banks to depositors or the FDIC, as a function of $r$ and $t$, under strategy 1 (and per unit deposited). Then $\Phi_{1}$ satisfies

$$
\Phi_{1}[r(1+t)] \equiv r(1+t)\{1-G[r(1+t)]\}+\int_{0}^{r(1+t)} z g(z) d z=r(1+t)-\int_{0}^{r(1+t)} G(z) d z .
$$

Clearly $\Phi_{1}^{\prime}>0$ holds, so increases in $r$ or the insurance premium $t$ raise the bank's cost of funds.

\section{c. Net Payoffs Under Strategy 1}

From our previous observations it is immediate that a bank's net expected profit under strategy 1 , and assuming that credit is rationed, is given by $q_{1}\left\{\pi\left(\hat{x}_{1}, q_{1} ; \gamma\right)-\Phi_{1}[r(1+t)]\right\}-\lambda p\left(\hat{x}_{1}\right)$. We now compare this with the expected payoffs available under other strategies open to a bank.

\section{Strategy 2}

Another option open to a bank would be simply to lend a borrower $q_{2}$. Under this strategy it is not feasible for a borrower to invest in project 1 or to divert funds, since if funds are diverted it will be clear that no project was undertaken. Thus, under strategy 2 a borrower just invests in project 2 , which is an alternative method of dealing with the moral hazard problem. ${ }^{25}$

When strategy 2 is followed, clearly no interim monitoring is necessary by the lender. Moreover, if $x_{2}$ denotes the interest rate charged, the borrower defaults if $z_{2}<x_{2}$. Thus the expected payment from the borrower to the bank is given by

$$
q_{2}\left\{x_{2}\left[1-F\left(x_{2}\right)\right]+\int_{0}^{x_{2}} z f(z) d z\right\}=q_{2}\left[x_{2}-\int_{0}^{x_{2}} F(z) d z\right] .
$$

Then the bank's expected return under strategy 2 (per unit lent), not inclusive of its cost of funds, but inclusive of ex post verification costs is given by 


$$
q_{2}\left[x_{2}-\int_{0}^{x_{2}} F(z) d z-\left(\frac{\gamma}{q_{2}}\right) F\left(x_{2}\right)\right] \equiv q_{2} \xi\left(x_{2}, q_{2} ; \gamma\right) .
$$

The remarks we made above about the nonmonotonicity of $\pi(-)$ apply equally to $\xi(-)$. It follows that, under credit rationing, a bank following strategy 2 will charge the interest $\operatorname{rate}^{26} x_{2}=\operatorname{argmax}_{x}$ $\xi\left(x, q_{2} ; \gamma\right) \equiv \hat{x}_{2}$, and its expected gross return (exclusive of its costs of funds) equals $q_{2} \xi\left(\hat{x}_{2}, q_{2} ; \gamma\right)$.

\section{a. The Cost of Funds}

A bank pursuing strategy 2 needs $q_{2}(1+t)$ units of funds to make its loans and pay its deposit insurance premiums. It will be feasible for the bank to pay its depositors $r q_{2}(1+t)$ iff its borrower has $z \geq r(1+t)$ : therefore the bank fails with probability $F[r(1+t)]$. If $\Phi_{2}[r(1+t)]$ denotes the expected payment by banks to depositors and the FDIC (per unit deposited) under strategy 2, it follows that

$$
\Phi_{2}[r(1+t)]=r(1+t)\{1-F[r(1+t)]\}-\int_{0}^{r(1+t)} z f(z) d z=r(1+t)-\int_{0}^{r(1+t)} F(z) d z .
$$

Assumption (a.1) implies that $\Phi_{2}[r(1+t)]<\Phi_{1}[r(1+t)]$; that is, the cost of funds per unit is lower under strategy 2 than under strategy 1 . It is also apparent that $\Phi_{2}^{\prime}>0$ holds.

\section{b. Net Payoffs Under Strategy 2}

From the preceding discussion it is apparent that a bank's net expected profits under strategy 2 are given by $q_{2}\left\{\xi\left(\hat{x}_{2}, q_{2} ; \gamma\right)-\Phi_{2}[r(1+t)]\right\}$, if credit is rationed.

\section{Strategy 3}

A bank engaged in strategy 1 or strategy 2 attempts to address the moral hazard problem in some form. There is a third option available to the bank: it might ignore moral hazard altogether. To be more specific, suppose that a bank lends $q_{1}$ to a borrower, that (a.2) holds, and that the bank 
engages in no interim monitoring. Then the borrower will invest in project 2 , and consume $q_{1}-q_{2}$ in "perks." 27 Under strategy 3 , the bank simply allows this to happen. ${ }^{28}$

In order to hide the fact that it is following strategy 3 , the bank must act as if it is following strategy 1. Then, in particular, it must charge the interest rate $\hat{x}_{1} \cdot{ }^{29}$ If it does so, since the borrower borrows $q_{1}$, a loan default occurs if $q_{2} z<q_{1} \hat{x}_{1}$. Thus the probability of default is $F\left[\left(q_{1} / q_{2}\right) \hat{x}_{1}\right]$, and the expected gross return to the bank-inclusive of ex post monitoring costs—is

$$
q_{1} \hat{x}_{1}\left\{1-F\left[\left(\frac{q_{1}}{q_{2}}\right) \hat{x}_{1}\right]\right\}+q_{2} \int_{0}^{\left(q_{1} / q_{2}\right) \hat{x}_{1}} z f(z) d z-\gamma F\left[\left(\frac{q_{1}}{q_{2}}\right) \hat{x}_{1}\right] \equiv q_{2} \xi\left[\left(\frac{q_{1}}{q_{2}}\right) \hat{x}_{1}, q_{2} ; \gamma\right]
$$

\section{a. Cost of Funds}

In order to pursue strategy 3 , a bank needs $q_{1}(1+t)$ units of funds to lend $q_{1}$ and pay its deposit insurance premium. The bank can pay depositors $r$ per unit deposited iff $q_{2} z \geq r q_{1}(1+t)$, since the bank's loans are invested in the small scale project (project 2). Thus the bank fails with probability $F\left[\left(q_{1} / q_{2}\right) r(1+t)\right]$, and the bank's expected payments to depositors and the FDIC are

$$
\begin{aligned}
& q_{1} r(1+t)\left\{1-F\left[\left(\frac{q_{1}}{q_{2}}\right) r(1+t)\right]\right\}+q_{2} \int_{0}^{\left(q_{1} / q_{2}\right) r(1+t)} z f(z) d z \\
& =q_{1} r(1+t)-q_{2} \int_{0}^{\left(q_{1} / q_{2}\right) r(1+t)} F(z) d z=q_{2} \Phi_{2}\left[\left(\frac{q_{1}}{q_{2}}\right) r(1+t)\right] .
\end{aligned}
$$

\section{b. Net Payoffs Under Strategy 3}

Consolidating the discussion of the preceding paragraphs, it is apparent that the net expected profit of a commercial bank pursuing strategy 3 is given by the expression $q_{2}\left\{\xi\left[\left(q_{1} / q_{2}\right) \hat{x}_{1}, q_{2} ; \gamma\right]-\right.$ $\left.\Phi_{2}\left[\left(q_{1} / q_{2}\right) r(1+t)\right]\right\}$. We now proceed to rank the different strategies available to a commercial bank. 


\section{B. A Comparison of Alternative Strategies}

In this section we pose the question: which lending strategy will be preferred by any given bank? The main result of the section is as follows.

PROPOSITION 1. For every commercial bank, strategy 2 is strictly preferred to strategy 3.

Proposition 1 is proved in Appendix A. The proposition makes a strong assertion: strategy 3 cannot be optimal under commercial banking. Thus a commercial bank will always take some actions to address the moral hazard problem confronting it, either by restricting the size of its loans, or by engaging in interim monitoring. As we will show, an analogous statement cannot be made under universal banking.

Intuitively, a bank pursuing strategy 3 holds a claim on the same assets as a bank following strategy 2. In addition, it is more constrained in its choice of a loan rate, and it must raise a larger quantity of deposits than a bank following strategy 2. Finally, it cannot share in the "perks" that accrue to the borrower under strategy 3 , since it has no ownership claim on the firm. Thus, a commercial bank will never choose to allow its borrowers to divert funds.

A comparison of strategies 1 and 2 is far less straightforward. From our previous discussion it is easy to show that any bank prefers strategy 1 to strategy 2 iff

$$
\begin{aligned}
\pi\left(\hat{x}_{1}, q_{1} ; \gamma\right) & -\left(\frac{\lambda}{q_{1}}\right) p\left(\hat{x}_{1}\right) \geq\left(\frac{q_{2}}{q_{1}}\right) \xi\left(\hat{x}_{2}, q_{2} ; \gamma\right)+\left(\frac{q_{1}-q_{2}}{q_{1}}\right) r(1+t) \\
& -\int_{0}^{r(1+t)}\left[G(z)-\left(\frac{q_{2}}{q_{1}}\right) F(z)\right] d z .
\end{aligned}
$$

The expression in (10) reflects several considerations that arise in ranking strategies 1 and 2. First, $\pi\left(\hat{x}_{1}, q_{1} ; \gamma\right)-\left(\lambda / q_{1}\right) p\left(\hat{x}_{1}\right)>\left(q_{2} / q_{1}\right) \xi\left(\hat{x}_{2}, q_{2} ; \gamma\right)$ holds iff $\lambda$ is sufficiently small. This expression is 
obviously necessary for the satisfaction of (10): strategy 1 is superior to strategy 2 only if the costs of interim monitoring are sufficiently small. ${ }^{30}$

Second, engaging in strategy 1 requires that the bank raise more funds than would be required to follow strategy 2. This is expensive, and it becomes more expensive as $r(1+t)$ increases. Thus high values of $r$, or high values of $t$-ceteris paribus—favor banks following strategy 2.

Third, the expected cost of ex post state verification under strategy 1 (2) equals $\gamma G\left(\hat{x}_{1}\right)$ $\left[\gamma F\left(\hat{x}_{2}\right)\right]$. If $F\left(\hat{x}_{2}\right)>G\left(\hat{x}_{1}\right)$ holds, ${ }^{31}$ then strategy 2 involves higher expected ex post monitoring costs than strategy 1. This works in favor of strategy 1. Moreover, this last observation has an interesting implication: other things being equal, higher ex post monitoring costs increase the attractiveness of strategy 1 relative to strategy 2 (if $F\left(\hat{x}_{2}\right)>G\left(\hat{x}_{1}\right)$ ). But, in general, as these observations make clear, either strategy 1 or strategy 2 might be preferred by any bank, depending on the configuration of parameters.

\section{Bank Heterogeneity, and Some Scenarios}

When there is heterogeneity among the set of potential bankers-as when there are low and high cost banks - there are several possible scenarios with respect to which banks operate, and with respect to which strategies they follow. We now outline some of the possibilities.

Scenario 1. If the interim and ex post monitoring costs of high cost banks are too high, then it is possible that only low cost banks will operate, in equilibrium. In this case the low cost banks may follow either strategy 1 or strategy 2.

Scenario 2. If low and high cost banks have relatively similar monitoring costs, then it is possible that both types of banks will operate and, moreover, that both types of banks will have the same optimal strategy. 
Of course when either scenario 1 or scenario 2 is played out—in equilibrium—nothing very interesting happens as a result of allowing for bank heterogeneity. Thus, when we want to discuss the implications of having different kinds of banks, we will focus on the third of our scenarios.

Scenario 3. High cost banks do not have monitoring costs that are so high as to deter them from operating. However, either the interim or the ex post monitoring costs of high and low cost banks differ sufficiently that they have different optimal strategies.

When scenario 3 transpires, it may be either the high, or the low cost banks that find it optimal to follow strategy 1 . It will be the low cost banks that follow strategy 1 when they have relatively low (and high cost banks have relatively high) interim monitoring costs, and when ex post monitoring costs are relatively similar across the banks. On the other hand, it will be high cost banks that favor strategy 1 if interim monitoring costs are similar across banks, if $F\left(\hat{x}_{2}\right)>G\left(\hat{x}_{1}\right)$, and if high cost banks have ex post monitoring costs that are enough higher than those of low cost banks.

The last point is of interest for the following reason. Under scenario 3, some banks follow strategy 1 , while others follow strategy 2 . The former set of banks will have a larger volume of loans and deposits, and a lower probability of failure. When interim monitoring cost differences differentiate high and low cost banks, the large banks will also have relatively low operating costs. But, when ex post monitoring cost differences differentiate these banks — and when $F\left(\hat{x}_{2}\right)>G\left(\hat{x}_{1}\right)$ — the relatively large banks will have high operating costs. In short, there is no logical presumption that it is the most efficient banks that are also the largest banks.

We will refer to scenario $3 \mathrm{a}(3 \mathrm{~b})$ as the situation where both types of banks operate, and low (high) cost banks follow strategy 1. Under scenario 3a (3b), equation (10) holds for low (high) cost banks, while the same equation fails for high (low) cost banks. 


\section{General Equilibrium}

It remains to determine a full general equilibrium of the model with commercial banking. There are two components to such a determination. First, the assumption that $\beta \geq \alpha$, coupled with the assumption that not all potential borrowers are funded (rationing of credit), implies that not all potential bankers can operate banks, in equilibrium. Thus the marginal banker must be indifferent between operating a bank and acting as a depositor. In effect, the marginal bank must earn a "normal" expected profit. Second, the FDIC must break even. We now proceed as follows.

We assume that the FDIC exogenously sets a value for the deposit insurance premium parameter $t$. Given $t$, the remaining endogenous variables in the model are the deposit interest rate, $r$, and the lump-sum tax levied by the FDIC, $\tau$. In particular, given $t$, the FDIC's expected losses depend on $r$, both directly and indirectly. ${ }^{32}$ Thus, in equilibrium, the lump-sum tax that the FDIC must impose to balance its budget needs to be determined along with $r$. We now describe the remaining equilibrium conditions of the model.

\section{1. "Normal" Profits for Banks}

We begin by stating the condition under which banks earn normal profits when all potential bankers are identical, ex ante. We then give the required modification when there is heterogeneity among potential bankers.

When all potential bankers are alike, agents who operate banks will either pursue strategy 1 or strategy 2. Then, as per our previous discussion, their expected profits will be given by

$$
\begin{aligned}
Q[r(1+t) ; \gamma, \lambda] \equiv & \max \left\{q_{1}\left[\pi\left(\hat{x}_{1}, q_{1} ; \gamma\right)-\left(\lambda / q_{1}\right) p\left(\hat{x}_{1}\right)-\Phi_{1}[r(1+t)]\right], q_{2}\left[\xi\left(\hat{x}_{2}, q_{2} ; \gamma\right)\right.\right. \\
& \left.\left.-\Phi_{2}[r(1+t)]\right]\right\} .
\end{aligned}
$$


On the other hand, agents who do not operate banks will simply become depositors. Such agents pay the lump-sum tax $\tau$, and deposit $1-\tau$ with a bank. Their payoff is $r(1-\tau)$. Thus, potential bankers are indifferent between operating and not operating a bank iff

$$
Q[r(1+t) ; \gamma, \lambda]=r(1-\tau)
$$

Given $t$, equation (12) describes a relation between $r$ and $\tau$ that is depicted in Figure 1 . The locus defined by (12) is upward sloping, since $Q$ is a decreasing function of $r$. Intuitively, as $\tau$ rises the FDIC is engaging in increasingly heavy subsidization of banks at the expense of depositors. Thus, to maintain an equality of payoffs the deposit rate of interest must rise. This benefits depositors and is costly to banks. Therefore $r$ and $\tau$ must move together if banks are to earn only normal profits.

\section{a. Heterogeneity}

When there are both low and high cost banks, matters are somewhat more complicated. In particular, depending on the fraction of low cost banks in the banker population $(\mu)$ and the extent of credit rationing, it may be the case that only low cost banks operate. Or, it is possible that both low and high cost banks operate. We describe each case in turn.

When only low cost banks operate, then the marginal banker obviously has low costs. Then (12) must be replaced with

$$
Q\left[r(1+t) ; \gamma_{L}, \lambda_{L}\right]=r(1-\tau)
$$

We now describe what is required in order for only low cost banks to operate, in equilibrium.

Let $\theta$ denote the fraction of borrowers who receive funding. When only one type of bank is active, each funded borrower gets $q_{1}\left(q_{2}\right)$ units of funds, if strategy 1 (2) is preferred by banks. Define the function $q[r(1+t)]$ by 


$$
q[r(1+t)]=\begin{aligned}
& q_{1} ; \quad \text { if strategy } 1 \text { is preferred (by a low cost bank) } \\
& q_{2} ; \quad \text { if strategy } 2 \text { is preferred (by a low cost bank) }
\end{aligned}
$$

Then "uses" of funds of given by $\theta \alpha q[r(1+t)]$.

With respect to "sources" of funds, there is unit one of funds supplied by every agent who is not an active bank or borrower. ${ }^{33}$ Since the measure of active banks must equal the measure of funded borrowers, sources of funds are $1-\alpha(1+\theta)$. Hence, an equality between sources and uses of funds requires that

$$
\theta=\left(\frac{1-\alpha}{\alpha}\right)\left\{\frac{1}{1+q[r(1+t)]}\right\}
$$

In order for it to be feasible for only low cost banks to operate, it must be the case that $\theta \alpha \leq$ $\mu \beta$ holds. Thus, a necessary (but not sufficient) condition for low cost banks alone to operate is that $\mu \beta\left(1+q_{1}\right) \geq 1-\alpha$. If this condition fails, some high cost banks must operate, in equilibrium.

Of course, if only low cost banks operate, there is no heterogeneity among active banks in our model. Therefore, in the future when we allow for bank heterogeneity, we will assume that some high cost banks operate. As we have noted, this will be the case if

$$
1-\alpha>\mu \beta\left(1+q_{1}\right)
$$

Moreover, when some high cost banks operate, clearly the marginal banker must be a high cost banker. Therefore the marginal banker earns zero profits iff

$$
Q\left[r(1+t) ; \gamma_{H}, \lambda_{H}\right]=r(1-\tau) .
$$

Finally, we have argued that heterogeneity among banks is interesting if and only if some banks follow strategy 1 , while others follow strategy 2. To fix ideas, we henceforth assume (when there 
are high and low cost banks) that low cost banks prefer strategy 1, while high cost banks prefer strategy $2 .^{34}$ Then (16) reduces to

$$
q_{2}\left\{\xi\left(\hat{x}_{2}, q_{2} ; \gamma_{H}\right)-\Phi_{2}[r(1+t)]\right\}=r(1-\tau)
$$

In addition, this configuration of optimal bank strategies requires that equation (10) be satisfied for low cost banks, while the same condition is violated for high cost banks.

\section{The FDIC "Break-Even" Condition}

As before, we begin by describing what is required for the FDIC to break even when all potential bankers are identical, ex ante. We then show how the analysis must be modified when there is bank heterogeneity.

Several factors need to be analyzed in order to state the condition that must be satisfied for the FDIC budget to balance. First, we must know "how many" banks are in operation. Second, we must know the expected loss of each bank. This, of course, depends on the optimal lending strategy of banks. Third, we must know the probability of failure for each bank, as this determines the FDIC's cost of ex post monitoring. This failure probability also depends on the banks' optimal loan strategy. We begin with the measure of banks that are active.

Our assumption of "one bank-one borrower" implies that the measure of active banks must equal the measure of funded borrowers. Thus, as indicated by equation (15), the mass of banks in operation is $\alpha \theta=(1-\alpha) /\{1+\mathrm{q}[\mathrm{r}(1+\mathrm{t})]\}$. For future reference we note that credit must be rationed $(\theta<1$ must hold $)$ if

$$
1-\alpha<\alpha\left(1+q_{2}\right)
$$

as we henceforth assume. 
When $\alpha \theta$ is the measure of active banks, the FDIC collects $\alpha \theta t \mathrm{q}[\mathrm{r}(1+\mathrm{t})]$ in deposit insurance premiums, and it collects $[1-\alpha(1+\theta)] \tau$ in lump-sum taxes paid by bank depositors. The FDIC, by assumption, reinvests this income in the credit market earning $r$ per unit deposited in period two. Thus total second period FDIC income - not inclusive of the assets of liquidated banks-is given by the expression

$$
r\{\alpha \theta t q[r(1+t)]+[1-\alpha(1+\theta)] \tau\}=r(1-\alpha)(t+\tau) q[r(1+t)] /\{1+q[r(1+t)]\}
$$

Total FDIC obligations in period 2 are calculated as follows. Each bank has an expected payment to depositors and the FDIC (if it fails) of $q_{1} \Phi_{1}[r(1+t)]\left(q_{2} \Phi_{2}[r(1+t)]\right)$, if strategy 1 (2) is optimal. Thus, by the law of large numbers, FDIC payments to depositors (including itself)—net of income from asset liquidation-equal $q_{1}\left\{r(1+t)-\Phi_{1}[r(1+t)]\right\}\left(q_{2}\left\{r(1+t)-\Phi_{2}[r(1+t)]\right\}\right)$ if strategy 1 (2) is being followed by banks. ${ }^{35}$ Multiplying the appropriate quantity by $\alpha \theta$ (the mass of active banks) gives the difference between FDIC obligations to the depositors of failed banks and FDIC income from asset liquidation.

The other revenue raised by the FDIC must cover this difference, and it must also cover the monitoring costs incurred by the FDIC in the process of asset liquidation. If banks are engaged in strategy $1(2)$, then a fraction $G[r(1+t)](F[r(1+t)])$ of banks fail, and the FDIC's costs of ex post state verification are $\gamma_{F} G[r(1+t)]\left(\gamma_{F} F[r(1+t)]\right)$. Then if $c[r(1+t)]$ denotes the second period costs of the FDIC — net of its income from liquidating the assets of failed banks- $c[r(1+t)]$ satisfies

$$
\begin{aligned}
c[r(1+t)]= & (1-\alpha)\left(\frac{q_{1}}{1+q_{1}}\right)\left\{r(1+t)-\Phi_{1}[r(1+t)]+\left(\frac{\gamma_{F}}{q_{1}}\right) G[r(1+t)]\right\} ; \text { if strategy } 1 \text { is optimal for banks } \\
& (1-\alpha)\left(\frac{q_{2}}{1+q_{2}}\right)\left\{r(1+t)-\Phi_{2}[r(1+t)]+\left(\frac{\gamma_{F}}{q_{2}}\right) F[r(1+t)]\right\} ; \text { if strategy } 2 \text { is optimal for banks }
\end{aligned}
$$


The FDIC breaks even iff

$$
r(1-\alpha)(t+\tau) q[r(1+t)] /\{1+q[r(1+t)]\}=c[r(1+t)] .
$$

We now depict the locus defined by (17) diagrammatically. It has several possible configurations, two of which are depicted in Figures 2.a and 2.b. In those figures, the optimal lending strategy for banks is strategy 1 (2) if $r(1+t)$ lies to the left (right) of the dotted vertical line. The function $c[r(1+t)]$ will typically not be continuous at the value of $r(1+t)$ that makes banks indifferent between the two strategies. Moreover, it is easy to show that $c[r(1+t)]$ can either increase or decrease as banks shift from strategy 1 to strategy 2, depending on parameter values. In Figure 2.a (2.b), the FDIC's costs rise (fall) discretely as the optimal strategy changes from strategy 1 to strategy 2.

If $G(z) / z$ and $F(z) / z$ are both nondecreasing in $z$, then it is straightforward to show that (17) defines a locus that is either monotonically increasing, as in Figure 2.a, or that fails to be increasing only when strategy 1 and strategy 2 yield the same expected payoff to a bank, as in Figure $2 . b .^{36,37}$ Of course, it is also possible that a single lending strategy is optimal for all values of $r(1+t)$ : in this case the locus defined by (17) is continuous.

The determination of $r$ and $\tau$ in a general equilibrium is depicted in Figure 3. As shown there, there is considerable scope for multiple equilibria to arise. Across different equilibria higher values of $r$ are accompanied by higher lump-sum taxes and larger FDIC losses. Of course, as shown in Figure 3.b, there need not be multiple equilibria for arbitrary configurations of parameter values.

\section{a. Bank Heterogeneity}

As before, when there are both high and low cost banks in operation we fix ideas by assuming that low (high) cost banks optimally follow strategy 1 (2) in lending. We now state the condition under which the FDIC breaks even when this transpires. 
We continue to denote the fraction of funded borrowers by $\theta$. Only funded borrowers who borrow from low cost banks get a loan of $q_{1}$; the $\theta \alpha-\mu \beta$ borrowers who borrow from high cost banks get a loan of $q_{2}$. Hence "uses" of funds are $\theta \alpha q_{2}+\mu \beta\left(q_{1}-q_{2}\right)$. As before, "sources" of funds are $1-\alpha(1+\theta)$. Thus, an equality between sources and uses of funds implies that

$$
\theta=\frac{1-\alpha-\mu \beta\left(q_{1}-q_{2}\right)}{\alpha\left(1+q_{2}\right)}
$$

Clearly, credit is rationed $(\theta<1$ holds) iff

$$
1<\alpha\left(2+q_{2}\right)+\mu \beta\left(q_{1}-q_{2}\right)
$$

In addition, high cost banks must be active if $\theta \alpha<\mu \beta$. This condition is satisfied iff

$$
1-\alpha>\mu \beta\left(1+q_{1}\right)
$$

When (18) and (19) hold, there are banks of mass $\mu \beta(\theta \alpha-\mu \beta)$ following strategy 1 (2). Thus, the FDIC collects $t\left[\theta \alpha q_{2}+\mu \beta\left(q_{1}-q_{2}\right)\right]$ in period 1 in deposit insurance premiums, and it also collects $\tau[1-\alpha(1+\theta)]$ in lump-sum taxes. It is then straightforward to show that the FDIC's second period income-not inclusive of income from the liquidation of failed banks—is given by

$$
r(t+\tau)\left\{(1-\alpha)\left(\frac{q_{2}}{1+q_{2}}\right)+\mu \beta\left(\frac{q_{1}-q_{2}}{1+q_{2}}\right)\right\} .
$$

In addition, the FDIC's net obligations to the depositors of the $\mu \beta G[r(1+t)]$ low cost banks that fail, plus its costs of monitoring these banks, equal $\mu \beta\left\{q_{1}\left[r(1+t)-\Phi_{1}[r(1+t)]\right]+\gamma_{F} G[r(1+t)]\right\}$. The FDIC's net obligations to the depositors of the $(\theta \alpha-\mu \beta) F[r(1+t)]$ high cost banks that fail, plus its costs of monitoring these banks, equal $(\theta \alpha-\mu \beta)\left\{q_{2}\left[r(1+t)-\Phi_{2}[r(1+t)]\right]+\gamma_{F} F[r(1+t)]\right\}$. It is then easy to show that the FDIC breaks even iff 


$$
\begin{aligned}
& r(t+\tau)\left\{(1-\alpha)\left(\frac{q_{2}}{1+q_{2}}\right)+\mu \beta\left(\frac{q_{1}-q_{2}}{1+q_{2}}\right)\right\} \\
& \quad=\mu \beta\left\{\gamma_{F} G[r(1+t)]+q_{1} \int_{0}^{r(1+t)} G(z) d z\right\}+(\theta \alpha-\mu \beta)\left\{\gamma_{F} F[r(1+t)]+q_{2} \int_{0}^{r(1+t)} F(z) d z\right\} .
\end{aligned}
$$

When (16') and (20) have a solution $(r, \tau)$ such that (10) holds (fails) for low (high) cost banks, then we indeed have an equilibrium where low (high) cost banks follow strategy 1 (2).

\section{Universal Banking}

In this section we analyze optimal bank behavior, as well as the determination of a full general equilibrium, under a system where all banks are universal banks. By this, of course, we mean simply that all banks take equity positions in the firms they "lend" to. ${ }^{38}$ In the next section we then compare universal with commercial banking.

When banks take an equity position in the firms operated by their borrowers, two things happen. First, the transfer between the firm and bank must always be nontrivially state contingent. Absent stochastic monitoring, this obligates the bank to engage in ex post state verification for (almost) all project return realizations. This observation implies that at a cost of $\gamma$, the bank in effect becomes fully informed about the investment return of the firm. There is, therefore, no gain from the bank and the borrower entering into any kind of contract other than an equity contract. Thus the bank is happy to take an equity position alone, rather than entering into a more complicated contractual arrangement that might have both a debt and an equity component.

Second, when a bank holds equity in a firm, it can share in the consumption of "perks" generated by the diversion of funds away from project investments. As we will show, this ability to share in "perks" consumption can substantially alter the set of optimal lending strategies for a bank. 
Throughout the analysis, we let $w \in[0,1]$ denote the share held by the bank in the firm's project. And, as before, there are only two claimants: the operator of the firm and the bank itself. (This arrangement can again be regarded as a type of delegated monitoring.) Finally, we assume that if a bank has a claim on a fraction $w$ of the firm's profits, it also has a claim on a fraction $w$ of the "perks" generated by any diversion of investment funds, if the bank has agreed to-and is aware of-this diversion. We now consider the strategies available to a universal bank.

\section{A. Bank Strategies}

As in Section II, we begin by taking the set of active banks and the rate of interest on deposits as given. We then investigate the optimal behavior of banks.

As before, there are only three strategies open to banks. A bank can transfer $q_{1}$ to a firm and-if there is a moral hazard problem—engage in interim monitoring to deter it. Or, a bank can transfer just $q_{2}$ to a firm and, de facto, force the firm to invest in project 2. Finally, a bank can transfer $q_{1}$ to a borrower with the idea that the borrower will invest in project 2 . In this case, the bank and the firm jointly expend $q_{1}-q_{2}$ on "perks." We now consider each strategy in turn.

\section{Strategy 1}

Suppose that a bank invests $q_{1}$ in an entrepreneur's project, and takes an equity position of $w_{1}$. Then the expected payoff to the entrepreneur is $\left(1-w_{1}\right) q_{1} \hat{z}_{1}$, if the entrepreneur invests in project 1 . On the other hand, if the entrepreneur invests in project 2, without the bank's knowledge, his expected payoff is $\left(1-w_{1}\right) q_{2} \hat{z}_{2}+\delta\left(q_{1}-q_{2}\right){ }^{39}$ Thus, there is a moral hazard problem-under strategy 1 -iff

$$
\hat{z}_{1}<\left(\frac{q_{2}}{q_{1}}\right) \hat{z}_{2}+\frac{\delta\left(q_{1}-q_{2}\right)}{\left(1-w_{1}\right) q_{1}} .
$$


It is easy to show that (a.2) implies the satisfaction of the above inequality. Thus, whenever there is a moral hazard problem for a commercial bank following strategy 1 , there is also a moral hazard problem for a universal bank following strategy 1. Therefore, a universal bank following strategy 1 must engage in interim monitoring.

Let $\tilde{p}$ denote the probability that a universal bank following strategy 1 will engage in interim monitoring. Clearly, $\tilde{p}$ must be set high enough to deter an entrepreneur from diverting funds. As in Section II, we assume that if funds are diverted, "perks" consumption occurs before the bank has an opportunity to liquidate the borrower's project. Thus, an entrepreneur who does divert funds enjoys utility $\delta\left(q_{1}-q_{2}\right)$ from "perks." In addition, with probability $1-\tilde{p}$, the diversion of funds will not be discovered, and the entrepreneur will have an expected second period income of $\left(1-w_{1}\right) q_{2} \hat{z}_{2}$. Thus, $\tilde{p}$ must be chosen to satisfy the incentive constraint

$$
q_{1}\left(1-w_{1}\right) \hat{z}_{1} \geq(1-\tilde{p}) q_{2}\left(1-w_{1}\right) \hat{z}_{2}+\delta\left(q_{1}-q_{2}\right)
$$

Since interim monitoring is costly, clearly $\tilde{p}$ will be chosen to satisfy (21) at equality.

As is clear from an inspection of (21), if the bank takes too large an equity position, it will not be possible to deter moral hazard under any circumstances. In effect, then, there is an upper bound on the equity position that can be taken by a bank following strategy 1 , and

$$
w_{1} \leq 1-\delta\left(q_{1}-q_{2}\right) / q_{1} \hat{z}_{1}
$$

must hold. When (22) is satisfied, equation (21) implies that a bank following strategy 1 will engage in interim monitoring with probability

$$
\tilde{p}=\left\{q_{2} \hat{z}_{2}-q_{1} \hat{z}_{1}+\left[\delta\left(q_{1}-q_{2}\right) /\left(1-w_{1}\right)\right]\right\} / q_{2} \hat{z}_{2} \equiv \tilde{p}\left(w_{1}\right)
$$


Clearly, $\tilde{p}^{\prime}\left(w_{1}\right)>0$ holds, for all $w_{1}$ satisfying (22) as a strict inequality. Moreover, since the bank must engage in ex post state verification in (almost) all states, the expected return to the bank-not inclusive of the cost of funds-from following strategy 1 is given by $w_{1} q_{1} \hat{z}_{1}-\lambda \tilde{p}\left(w_{1}\right)-\gamma$.

\section{a. Cost of Funds}

A bank following strategy 1 requires $q_{1}(1+t)$ units of funds to make its loan(s) and to pay its deposit insurance premiums. Then the bank fails iff $z<r(1+t) / w_{1}$ holds ex post. ${ }^{40}$ It follows that the bank's expected payments to depositors and the FDIC (in the event of a failure) equal

$$
q_{1}\left\{r(1+t)\left[1-G\left(\frac{r(1+t)}{w_{1}}\right)\right]+w_{1} \int_{0}^{r(1+t) / w_{1}} z g(z) d z\right\}=w_{1} q_{1} \Phi_{1}\left[\frac{r(1+t)}{w_{1}}\right]
$$

Finally, we note that a universal bank will be willing to follow strategy 1 only if

$$
r(1+t) / \bar{z}<w_{1}
$$

Equation (24) implies that the bank will not fail with probability one.

\section{b. Net Expected Payoffs Under Strategy 1}

It follows from our previous observations that a bank's net expected profit under strategy 1 equals

$$
w_{1} q_{1} \hat{z}_{1}-\lambda \tilde{p}\left(w_{1}\right)-\gamma-w_{1} q_{1} \Phi_{1}\left[\frac{r(1+t)}{w_{1}}\right] \equiv \rho\left(w_{1}\right)
$$

The definition of $\Phi_{1}$ implies that $\rho\left(w_{1}\right) \geq 0$ holds iff $w_{1}$ satisfies

$$
q_{1} \hat{z}_{1}+q_{1} \int_{0}^{r(1+t) / w_{1}} G(z) d z \geq q_{1}\left[\frac{r(1+t)}{w_{1}}\right]+\left(\frac{\gamma}{w_{1}}\right)+\left(\frac{\lambda}{w_{1}}\right) \tilde{p}\left(w_{1}\right)
$$


It will subsequently prove useful to know how the bank's expected net profit varies with the bank's equity position. Proposition 2 states a result on this issue.

PROPOSITION 2. Suppose that

$$
(\gamma+\lambda) / \lambda \geq q_{1} \hat{z}_{1}\left[q_{1} \hat{z}_{1}-\delta\left(q_{1}-q_{2}\right)\right] / q_{2} \hat{z}_{2} \delta\left(q_{1}-q_{2}\right)
$$

holds. Then $\rho^{\prime}\left(w_{1}\right)>0$ for all $w_{1}$ satisfying (22) and (25).

Proposition 2 is proved in Appendix B. The proposition asserts that if $\gamma$ is large enough relative to $\lambda$, then a bank's expected profit under strategy 1 is increasing in $w_{1}$, for all feasible values of $w_{1}$ consistent with non-negative expected profits. We henceforth assume that (a.6) is satisfied.

\section{Strategy 2}

Under strategy 2, a bank invests $q_{2}$ in an entrepreneur's project, and this entitles the bank to a share $w_{2}$ of the borrower's investment return. ${ }^{41}$ Since any diversion of funds is impossible, there is no moral hazard problem. Clearly, then, the lender's expected return from following strategy 2-not inclusive of his cost of funds-is $w_{2} q_{2} \hat{z}_{2}-\gamma$.

\section{a. Cost of Funds}

A bank following strategy 2 must raise $q_{2}(1+t)$ units of funds to make loans of $q_{2}$, and to pay a deposit insurance premium of $t q_{2}$. Thus, a bank engaged in strategy 2 can pay $r$ per unit deposited in the second period iff $w_{2} z \geq r(1+t)$. It follows that the bank will fail with probability $F\left[r(1+t) / w_{2}\right]$. In addition, the bank's expected second period payments to depositors and the FDIC are given by

$$
q_{2}\left\{r(1+t)\left[1-F\left[\frac{r(1+t)}{w_{2}}\right]\right]+w_{2} \quad \int_{0}^{r(1+t) / w_{2}} z f(z) d z\right\}=w_{2} q_{2} \Phi_{2}\left[\frac{r(1+t)}{w_{2}}\right] .
$$




\section{b. Net Expected Profits Under Strategy 2}

It follows from these remarks that a bank pursuing strategy 2 has a net expected profit of $w_{2} q_{2}\left\{\hat{z}_{2}-\Phi_{2}\left[r(1+t) / w_{2}\right]\right\}-\gamma$.

\section{Strategy 3}

The third strategy available to a universal bank is as follows. The bank lends a borrower $q_{1}$ with the intention that the borrower will invest in project 2 , and divert $q_{1}-q_{2}$ units of funds towards expenditures on "perks" consumption. The bank claims a fraction, $w_{3}$, of both the ex post project return, and of "perks" consumption.

Under this strategy, the expected payoff of the entrepreneur is $\left(1-w_{3}\right)\left[q_{2} \hat{z}_{2}+\delta\left(q_{1}-q_{2}\right)\right]$. If instead the entrepreneur could invest in project 1 , his expected income would be $\left(1-w_{3}\right) q_{1} \hat{z}_{1}$. Since

our assumptions imply that $q_{1} \hat{z}_{1}>q_{2} \hat{z}_{2}+\delta\left(q_{1}-q_{2}\right)$, the entrepreneur clearly prefers to invest in project 1 . However, if he does so, no "perks" consumption will be generated, and the bank will be alerted that the firm has deviated from the intended investment strategy. Thus, by threatening to liquidate the investment if no "perks" consumption occurs, the bank can deter the entrepreneur from investing in project 1 . Or, in other words, under strategy 3 there is no costly moral hazard problem that arises between the bank and the firm. In effect, in this situation, a universal bank can exercise its control rights over the firm.

It follows that the expected net return to the bank from following strategy 3 -inclusive of "perks" consumption, but not inclusive of the cost of funds-is given by $w_{3}\left[q_{2} \hat{z}_{2}+\delta\left(q_{1}-q_{2}\right)\right]$.

\section{a. Cost of Funds}

A bank pursuing strategy 3 needs deposits in the amount $q_{1}(1+t)$ to make a loan of $q_{1}$ and to cover its deposit insurance premiums. The bank will therefore be able to pay its depositors in the second period iff its second period income, $w_{3} q_{2} z$, is no less than $r q_{1}(1+t)$. In other words, the bank 
fails with probability $F\left[\left(q_{1} / q_{2}\right) r(1+t) / w_{3}\right]$. And, the bank's expected second period payments to its depositors and to the FDIC equal

$$
\begin{gathered}
q_{1}\left\{r(1+t)\left[1-F\left[\left(\frac{q_{1}}{q_{2}}\right) \frac{r(1+t)}{w_{3}}\right]\right]+\left(\frac{q_{2}}{q_{1}}\right) w_{3} \int_{0}^{\left(q_{1} / q_{2}\right) r(1+t) / w_{3}} z f(z) d z\right\} \\
=q_{2} w_{3} \Phi_{2}\left[\left(\frac{q_{1}}{q_{2}}\right) \frac{r(1+t)}{w_{3}}\right] .
\end{gathered}
$$

b. Net Expected Profits Under Strategy 3

It follows from our discussion that a bank's net expected profit from following strategy 3 is equal to $w_{3}\left[q_{2} \hat{z}_{2}+\delta\left(q_{1}-q_{2}\right)\right]-\gamma-q_{2} w_{3} \Phi_{2}\left[q_{1} r(1+t) / q_{2} w_{3}\right]$

\section{B. A Determination of the Equity Positions}

We now discuss how the value of a bank's equity position is determined under each of the three possible bank strategies. In each case we proceed as in Section II, and assume that societal savings are insufficient to meet all of the potential demand for funds. ${ }^{42}$ In Section II this led to the rationing of credit. As we will show, matters may be different when banks can hold equity positions in firms. We begin with the determination of $w_{1}$.

\section{Strategy 1}

Assumption (a.6) implies that any bank's expected profits—under strategy 1-are increasing in $w_{1}$ (for all feasible values of $w_{1}$ consistent with non-negative expected profits). Thus, competition among entrepreneurs for funds implies that $w_{1}$ must be bid up to the lower of two values: $w_{1}$ must either be bid up to its largest feasible level, or it must be bid up to the level at which there is no longer competition for funds. Under strategy 1 funded entrepreneurs receive the expected payoff $\left(1-w_{1}\right) q_{1} \hat{z}_{1} ;$ thus competition for funds ceases when $\left(1-w_{1}\right) q_{1} \hat{z}_{1}=\bar{u}$. 
Define the value $\bar{w}_{1}$ by

$$
\bar{w}_{1}=\min \left\{\left(\frac{q_{1} \hat{z}_{1}-\bar{u}}{q_{1} \hat{z}_{1}}\right),\left(\frac{q_{1} \hat{z}_{1}-\delta\left(q_{1}-q_{2}\right)}{q_{1} \hat{z}_{1}}\right)\right\} .
$$

The argument just given implies that when banks follow strategy $1, w_{1}=\bar{w}_{1}$ holds.

$$
\begin{aligned}
& \text { If } \\
& \delta\left(q_{1}-q_{2}\right)>\bar{u}
\end{aligned}
$$

is satisfied, then under strategy 1 there will be unfunded borrowers who would like to get funding. They cannot, because if they offer a banker a larger equity claim, strategy 1 will cease to be feasible. Thus, the pursuit of strategy 1 by banks can be consistent with a phenomenon analogous to credit rationing. To fix ideas, we henceforth assume that (a.7) holds.

\section{Strategy 2}

It is straightforward to show that the expected profit of a bank following strategy $2, w_{2} q_{2} \hat{z}_{2}-$ $\gamma-w_{2} q_{2} \Phi_{2}\left[r(1+t) / w_{2}\right]$, is monotonically increasing in $w_{2}$. Hence, competition among entrepreneurs for funds implies that $w_{2}$ must be bid up to the level where a borrower is just indifferent between receiving and not receiving funding. Since a funded borrower under strategy 2 receives the expected payoff $\left(1-w_{2}\right) q_{2} \hat{z}_{2}$, it follows that

$$
w_{2}=\left(q_{2} \hat{z}_{2}-\bar{u}\right) / q_{2} \hat{z}_{2}
$$

\section{Strategy 3}

The expected profit a bank receives when it follows strategy $3, w_{3}\left[q_{2} \hat{z}_{2}+\delta\left(q_{1}-q_{2}\right)\right]-\gamma-$ $w_{3} q_{2} \Phi_{2}\left[\left(q_{1} / q_{2}\right) r(1+t) / w_{3}\right]$, is also increasing in $w_{3}$. Thus, a repetition of the argument just given 
implies that $w_{3}$ must be bid up until funded and unfunded borrowers receive the same expected utility. Since a funded borrower has the expected utility level $\left(1-w_{3}\right)\left[q_{2} \hat{z}_{2}+\delta\left(q_{1}-q_{2}\right)\right]$, it follows that

$$
w_{3}=\frac{q_{2} \hat{z}_{2}+\delta\left(q_{1}-q_{2}\right)-\bar{u}}{q_{2} \hat{z}_{2}+\delta\left(q_{1}-q_{2}\right)} .
$$

\section{A Comparison of Alternative Strategies}

We now consider the relative rankings of the strategies available to a universal bank. We begin with a comparison of strategies 1 and 3 .

\section{Strategy 1 vs. Strategy 3}

When (a.7) holds, we have $w_{1}=\left[q_{1} \hat{z}_{1}-\delta\left(q_{1}-q_{2}\right)\right] / q_{1} \hat{z}_{1}$, and the expected profit of a bank under strategy 1 is given by ${ }^{43}$

$$
w_{1} q_{1} \hat{z}_{1}-\gamma-\lambda-q_{1} r(1+t)+w_{1} q_{1} \int_{0}^{r(1+t) / w_{1}} G(z) d z
$$

In addition, $w_{3}=\left[q_{2} \hat{z}_{2}+\delta\left(q_{1}-q_{2}\right)-\bar{u}\right] /\left[q_{2} \hat{z}_{2}+\delta\left(q_{1}-q_{2}\right)\right]$, and the expected profit of a bank pursuing strategy 3 equals

$$
w_{3}\left[q_{2} \hat{z}_{2}+\delta\left(q_{1}-q_{2}\right)\right]-\gamma-q_{1} r(1+t)+q_{2} w_{3} \int_{0}^{\left(q_{1} / q_{2}\right) r(1+t) / w_{3}} F(z) d z .
$$

We now state a result on the relative rankings of strategies 1 and 3 .

PROPOSITION 3. Strategy 3 is preferred to strategy 1, under universal banking if,

$$
\lambda+\left[\delta\left(q_{1}-q_{2}\right)-\bar{u}\right]>q_{1} \hat{z}_{1}-q_{2} \hat{z}_{2}-\delta\left(q_{1}-q_{2}\right) .
$$


Proposition 3 is proved in Appendix C. The proposition asserts that a universal bank will prefer strategy 3 to strategy 1 if either $\lambda$ or $\left[\delta\left(q_{1}-q_{2}\right)-\bar{u}\right]$ is relatively large, and if project 1 is not too productive relative to project 2 (inclusive of the "perks" consumption made possible by the diversion of funds.)

When (29) holds, the relative ranking of strategies 1 and 3 under universal banking is exactly the opposite of their ranking under commercial banking. Why is this the case? There are three basic answers to this question.

First, when (a.7) holds, there is a strict upper limit on how large $w_{1}$ can be while strategy 1 is still feasible. This is not true under strategy 3. Thus, strategy 3 allows a bank to own a larger fraction of a firm than is possible under strategy 1. In effect, even though the total "surplus" (not inclusive of the cost of funds) is larger under strategy 1, the bank gets a larger fraction of this surplus under strategy 3. When (29) holds, the bank prefers a larger fraction of a smaller "pie."

Second, the bank's cost of funds is always lower under strategy 3 than under strategy 1 here. $^{44}$ In particular, by following strategy 3 a bank fails more often, ceteris paribus, and passes larger expected costs to the FDIC.

Third, a universal bank has a greater opportunity to share in the "perks" generated by the diversion of funds than does a commercial bank. By itself, though, this factor would be insufficient to induce a universal bank to pursue strategy 3 . The other two factors we have mentioned must be present for the bank to prefer strategy 3 .

\section{A Remark}

When $\tilde{p}\left(w_{1}\right)=1$ holds, strategy 1 is socially preferred to strategy 3 iff

$$
q_{1} \hat{z}_{1}-q_{2} \hat{z}_{2}-\delta\left(q_{1}-q_{2}\right)>\lambda
$$


Equation (30) asserts that the expected net return from investing $q_{1}$ in project 1 -and engaging in interim monitoring-exceeds the expected net return from investing $q_{2}$ in project 2 , and from consuming $q_{1}-q_{2}$ in "perks." Note that (29) and (30) can hold simultaneously. Thus, it can easily be the case that universal banking provides banks with perverse investment incentives, from a social perspective.

2. Strategy 2 vs. Strategy 3

We now compare the expected profits yielded by strategy 2 and by strategy 3, under universal banking. For a universal bank following strategy 2, expected profits are

$$
w_{2} q_{2} \hat{z}_{2}-\gamma-q_{2} r(1+t)+q_{2} w_{2} \int_{0}^{r(1+t) / w_{2}} F(z) d z
$$

In addition, $w_{2}=\left(q_{2} \hat{z}_{2}-\bar{u}\right) / q_{2} \hat{z}_{2}$. It follows that a universal bank prefers strategy 3 to strategy 2 iff

$$
q_{2} w_{3} \int_{0}^{\left(q_{1} / q_{2}\right) r(1+t) / w_{3}} F(z) d z-q_{2} w_{2} \int_{0}^{r(1+t) / w_{2}} F(z) d z>[r(1+t)-\delta]\left(q_{1}-q_{2}\right)
$$

is satisfied. We now state a result giving sufficient conditions for strategy 3 to be preferred to strategy 2.

PROPOSITION 4. (a) $q_{1} w_{2}>q_{2} w_{3}$ holds iff

$$
q_{2} \hat{z}_{2}\left[q_{2} \hat{z}_{2}+\delta\left(q_{1}-q_{2}\right)\right]>\bar{u}\left(q_{2} \hat{z}_{2}+\delta q_{1}\right)
$$

(b) Strategy 3 generates higher expected profits for a universal bank if (32) is satisfied, and if

$$
w_{2} \quad \int_{r(1+t) / w_{2}}^{\left(q_{1} w_{2} / q_{2} w_{3}\right) r(1+t) / w_{2}} F(z) d z \geq[r(1+t)-\delta]\left(q_{1}-q_{2}\right) / q_{2} .
$$

(c) A sufficient condition for (33) to hold is that (32) and 


$$
F\left[\frac{r(1+t)}{w_{2}}\right]\left[\hat{z}_{2}-\delta\left(\frac{q_{1}}{q_{2}}\right)\right] \geq \hat{z}_{2}[r(1+t)-\delta] / r(1+t)
$$

be satisfied.

The proof of proposition 4 appears in Appendix D. The proposition asserts that a universal bank will pursue strategy 3 over strategy 2 if (a) $\bar{u}$ is sufficiently small, (b) $\left(q_{2} / q_{1}\right) \hat{z}_{2}>\delta,{ }^{45}$ and (c) $r(1+t)$ is sufficiently close to $\delta$. In particular, there will be a relatively severe moral hazard problem under universal banking when the real rate of interest of deposits is relatively low, when the deposit insurance premium is relatively low, when "perks" are a relatively good substitute for other income, and when banks have considerable power to extract surplus from "borrowers."

We henceforth assume that (29) and the conditions of proposition 4 are satisfied. ${ }^{46}$ Then all active banks will pursue strategy 3, in equilibrium. It will therefore be the case that universal banking creates a severe moral hazard problem: banks do not attempt to control—and, in fact they condone-the diversion of funds by borrowers. This clearly constitutes a marked contrast with the situation under commercial banking.

\section{A General Equilibrium}

As in Section II, there are two requirements of equilibrium beyond what we have discussed thus far. First, the "marginal" bank must earn a "normal" expected profit. Second, the FDIC must break even. We now describe the corresponding equilibrium conditions.

When all banks follow strategy 3 , each active bank earns the expected profit $w_{3}\left\{q_{2} \hat{z}_{2}+\right.$ $\left.\delta\left(q_{1}-q_{2}\right)-q_{2} \Phi_{2}\left[\left(q_{1} / q_{2}\right) r(1+t) / w_{3}\right]\right\}-\gamma$, with $w_{3}=\left[q_{2} \hat{z}_{2}+\delta\left(q_{1}-q_{2}\right)-\bar{u}\right] /\left[q_{2} \hat{z}_{2}+\delta\left(q_{1}-q_{2}\right)\right]$. Agents who could operate banks, but choose not to, pay the lump-sum tax $\tau$, and deposit $1-\tau$. In the second period their utility is $\mathrm{r}(1-\tau)$. Hence, active banks earn "normal" profits iff ${ }^{47}$ 


$$
w_{3}\left[q_{2} \hat{z}_{2}+\delta\left(q_{1}-q_{2}\right)\right]-\gamma=r(1-\tau)+w_{3} q_{2} \Phi_{2}\left[\left(\frac{q_{1}}{q_{2}}\right) \frac{r(1+t)}{w_{3}}\right] .
$$

Equation (35) is depicted diagrammatically in Figure 4.

In order to describe what is required for the FDIC to break even, we must first describe the mass of active banks. As before, let $\theta$ denote the fraction of funded borrowers. Under our assumptions each funded borrower obtains $q_{1}$ units of funds. Thus, "uses" of funds is $\alpha \theta q_{1}$. "Sources" of funds derive from the single unit saved by agents who neither borrow, nor operate banks. Hence, sources of funds are $1-\alpha(1+\theta)$. Then sources and uses of funds are equated when

$$
\theta=(1-\alpha) / \alpha\left(1+q_{1}\right)
$$

Our previous assumptions imply that $\theta<1$, and the mass of funded borrowers and-by implication-active banks is $\theta \alpha=(1-\alpha) /\left(1+q_{1}\right)$.

Each funded borrower, as we have noted, receives a loan of $q_{1}$. It follows that the FDIC collects $\theta \alpha q_{1} t=t(1-\alpha) q_{1} /\left(1+q_{1}\right)$ in deposit insurance premiums in the first period, and [1 $\alpha(1+\theta)] \tau=\tau(1-\alpha) q_{1} /\left(1+q_{1}\right)$ in lump-sum taxes. Since all revenues are deposited, in period two the FDIC has income of $r(1-\alpha)(t+\tau) q_{1} /\left(1+q_{1}\right)$, not inclusive of the income generated by liquidating failed banks.

When all banks follow strategy 3 , a fraction $F\left[\left(q_{1} / q_{2}\right) r(1+t) / w_{3}\right]$ of all banks will fail in the second period. Hence, the FDIC incurs monitoring costs of $\gamma_{F} F\left[\left(q_{1} / q_{2}\right) r(1+t) / w_{3}\right]$. In addition, the FDIC's obligations to the depositors of failed banks-less the FDIC's income from bank asset liquidation-is given by $q_{1} r(1+t)-w_{3} q_{2} \Phi_{2}\left[\left(q_{1} / q_{2}\right) r(1+t) / w_{3}\right]$. Thus, the FDIC breaks even if

$$
r(1-\alpha)(t+\tau) q_{1} /\left(1+q_{1}\right)=q_{1} r(1+t)-w_{3} q_{2} \Phi_{2}\left[\left(\frac{q_{1}}{q_{2}}\right) \frac{r(1+t)}{w_{3}}\right]-\gamma_{F} F\left[\left(\frac{q_{1}}{q_{2}}\right) \frac{r(1+t)}{w_{3}}\right] .
$$


Equation (36) is depicted diagrammatically in Figure 4 under the assumption that $F(z) / z$ is nondecreasing in $z$. If (35) and (36) have a solution where $r(1+t)$ satisfies (31), then there is an equilibrium where all active banks follow strategy 3. And, clearly, multiple equilibria are a real possibility.

\section{A Comparison of Commercial vs. Universal Banking}

In Section II we exogenously imposed that all banks were commercial banks (as would be the case if banks were precluded from taking equity positions). We then derived optimal bank behavior, and the requirements of a general equilibrium under this assumption. In Section III, we exogenously imposed that all banks take equity positions. We similarly derived optimal bank behavior —and the conditions of a general equilibrium - under this requirement. In this section we endogenize bank choices over whether to acquire debt or equity claims on "borrowers." In particular, we now pose the following question: taking $r$ and $t$ as given, when would any individual bank prefer to take an equity position in a firm, rather than to hold a debt claim? When the values of $r$ and $\tau$ that satisfy (35) and (36) — as well as the exogenously given value of $t$-imply that each active bank would prefer an equity position to a debt claim, then there is indeed an equilibrium where all banks prefer to operate as universal rather than commercial banks. When this transpires, we have seen that moral hazard in banking can potentially become a severe problem, if universal banking is permitted. ${ }^{48}$

To fix ideas, in this section we proceed as follows. We assume that all potential bankers are identical, ex ante. We also assume that strategy 2 is the optimal lending strategy under commercial banking, while strategy 3 is the optimal strategy under universal banking. ${ }^{49}$ Under these assumptions, the expected profit of a universal bank is

$$
q_{2} \hat{z}_{2}+\delta\left(q_{1}-q_{2}\right)-\bar{u}-\gamma-q_{1} r(1+t)+q_{2} w_{3} \int_{0}^{\left(q_{1} / q_{2}\right) r(1+t) / w_{3}} F(z) d z
$$


with $w_{3}=\left[q_{2} \hat{z}_{2}+\delta\left(q_{1}-q_{2}\right)-\bar{u}\right] /\left[q_{2} \hat{z}_{2}+\delta\left(q_{1}-q_{2}\right)\right]$. The expected profit of a commercial bank is

$$
q_{2}\left\{\zeta\left(\hat{x}_{2}, q_{2} ; \gamma\right)-\Phi_{2}[r(1+t)]\right\}=q_{2}\left(\hat{x}_{2}-\int_{0}^{\hat{x}_{2}} F(z) d z\right)-\gamma F\left(\hat{x}_{2}\right)-q_{2} r(1+t)+\int_{0}^{r(1+t)} F(z) d z .
$$

In addition, in order for borrowers to take debt contracts, it must be the case that the expected utility of a funded borrower is no less than $\bar{u}$. In other words,

$$
q_{2} \hat{z}_{2}-q_{2}\left[\hat{x}_{2}-\int_{0}^{\hat{x}_{2}} F(z) d z\right] \geq \bar{u}
$$

must hold.

It follows that from these observations that a bank would strictly prefer an equity position over a debt claim if

$$
\begin{aligned}
q_{2} \hat{z}_{2}-q_{2}\left[\hat{x}_{2}-\int_{0}^{\hat{x}_{2}} F(z) d z\right]-\bar{u}+\delta\left(q_{1}-q_{2}\right)-\gamma\left[1-F\left(\hat{x}_{2}\right)\right] \\
+q_{2} w_{3} \int_{0}^{\left(q_{1} / q_{2}\right) r(1+t) / w_{3}} F(z) d z-q_{2} \int_{0}^{r(1+t)} F(z) d z>r(1+t)\left(q_{1}-q_{2}\right)
\end{aligned}
$$

is satisfied. We now state a condition under which (38) holds.

Proposition 5. Suppose that

$$
\left(q_{1}-q_{2}\right)\{\delta-r(1+t)[1-F(r(1+t))]\} \geq \gamma\left[1-F\left(\hat{x}_{2}\right)\right]
$$

Then equation (38) is satisfied.

Proposition 5 is proved in Appendix E. The proposition indicates that any bank given a choice will operate as a universal bank if (a) $\delta$ is sufficiently large ("perks" consumption is a good substitute for 
other income), (b) the probability of failure as a commercial bank $(F[r(1+t)])$ is sufficiently large, and (c) the cost of ex post state verification, $\gamma$, is sufficiently small. Note in particular that the main disadvantage of universal banking stems from the large amount of ex post monitoring that it requires. When ex post monitoring is not very costly, this does not serve as a strong deterrent to banks taking equity positions.

Finally, we note that proposition 5 gives a relative weak sufficient condition for banks to prefer equity positions over debt claims. It is by no means necessary that $\delta>r(1+t)\{1-F[r(1+t)]\}$ hold in order for equity positions to be desired.

\section{Conclusions}

Many claims have been made about the potential benefits, and the potential costs, of adopting a system of universal banking in the United States. Opponents of a universal banking system have argued that universal banking can easily exacerbate problems of moral hazard, and increase_-perhaps dramatically - the potential insurance obligations of the FDIC relative to a system of commercial banking.

For at least some configurations of parameter values, our analysis is quite supportive of these arguments. And, even when universal banking does not increase the severity of moral hazard problems in our model, a bank given the choice between a debt claim and an equity position will choose to hold equity largely because this either enables it to extract a larger portion of the profits from investment, or to pass a larger portion of its costs onto the FDIC. Universal banks, in short, have few intrinsic efficiency advantages over commercial banks in the world we have described.

One might suspect that this fact is due entirely to our focus on an environment where costly state verification problems are present in financial markets. As is well-known (Diamond 1984, GaleHellwig 1985, and Williamson 1986, 1987), the existence of costly state verification tends to favor 
debt as an optimal contractual form. However, our results go well beyond this observation. Indeed, they indicate conditions under which debt instruments are also well-suited to addressing problems of moral hazard. This result was not previously known, at least to us. Moreover, it is the case that one can easily obtain close analogs of our results in a pure risk-shifting model where costly state verification is entirely absent. Thus, we believe that our results will obtain in a much broader class of economies than just the one we have described here.

Another feature of our analysis that merits comment is as follows. In practice, many believe that the benefits of universal banking derive from the fact that that arrangement allows banks to hold both debt and equity claims on firms. As we have noted, our model has the property that a bank taking an equity position in a firm has no reason to acquire a debt claim as well. Thus it may appear that in this way we have "stacked the deck" against universal banking. However, we do not believe this to be the case. Our main points are that (a) the ability to take equity positions aligns the incentives of banks and borrowers-potentially at the expense of the FDIC, (b) that when funds are scarce, the ability to take equity positions enables banks to extract additional surplus from borrowers, and (c) banks may be able to extract maximum surplus by distorting resource allocations. We see no reason why these points should be overturned by finding an environment in which there is a simultaneous role for both debt and equity claims.

Finally, a crucial aspect of our model is the assumption that banks can share in "perks" consumption iff they hold an equity position in a firm. What do we have in mind here? While harder to model than "perks" consumption, in practice large universal banks hold control rights in any number of different firms. This enables them to engineer transactions among these firms that are beneficial to the bank-although not necessarily beneficial to all parties to the transaction or their other outside claimants. These powers would be harder to exercise with no equity positions in firms. Thus, for us, "perks" consumption stands in broadly for an ability to benefit at the expense of other 
claimants by taking hidden actions. We think it is highly plausible that this ability is enhanced by holding an equity position in a firm. ${ }^{50}$

As a last remark, we wish to emphasize that when credit is rationed, a system of universal banking substantially alters the set of conditions that determine a full general equilibrium in any given economy. This observation argues for a broader use of general equilibrium methods to evaluate the relative merits of commercial versus universal banking. This is a topic we hope to pursue in greater detail in the course of future research. 
${ }^{1}$ The key legislation which constrains U.S. banks equity investments is the Glass-Steagall Act of 1933. However, a number of other laws also pertain to this issue, particularly the Bank Holding Company Act of 1956 and its 1970 amendments. Incidentally, there are some important exceptions to the equity investment prohibition. In default situations, banks are permitted to restructure loans into equity positions with the requirement of divestiture after a few years (see James 1993). Also, bank holding companies are permitted to form (separately capitalized) venture capital subsidiaries for the expressed purpose of investing in start up enterprises.

${ }^{2}$ The different banking regulations undoubtedly affect the entire financial intermediary sector, not just banks. Restrictions on commercial banking activities have contributed to the development of a large and active stock market in the United States. Not incidentally, the capitalization of the German stock market is relatively small, and characterized by thin trading and few listings compared to the United States (Gorton and Schmid 1996).

${ }^{3}$ For example, the so-called Shadow Financial Regulatory Committee favors adoption of a universal banking system in the United States. See "Criticism of Financial Reform Overblown, Shadow Panel Says," American Banker, May 6, 1997.

${ }^{4}$ As we show, in our model banks derive no advantage by taking "mixed" positions consisting of combinations of debt and equity.

${ }^{5}$ In the last several years, an attempt has been made (pursuant to the provisions of the FDICIA Act of 1991) to set deposit insurance premia according to an insured bank's risk class. However, a simple flat rate insurance scheme is still a good approximation to reality in the United States, for the overwhelming majority of banks are categorized in the same (lowest) risk class.

${ }^{6}$ Santos' model structure is rather different than ours and produces different conclusions. In his analysis, when the bank is restricted to making loans (commercial banking) the borrower will 
undertake riskier projects than it would under universal banking. Santos does not consider the monitoring role of banks in controlling the firm's moral hazard problem.

${ }^{7}$ In addition, Boyd and Smith (1994) argue that—for realistic parameter values_-the welfare gains from stochastic monitoring are likely to be small.

${ }^{8}$ This "diversion of funds" formulation is related to that of Gertler and Hubbard (1988) or Gertler and Rogoff (1990). The assumption that $\delta \leq 1$ implies that expenditures on "perks" never generate more utility than an equivalent amount of income. In effect, $\delta$ indexes how good a substitute "perks" are for other income. The assumption that $\hat{z}_{2}>\delta$ holds implies that investments in project 2 are more productive than expenditures on "perks" consumption (not inclusive of the costs of state verification).

${ }^{9}$ Again this cost may differ across agents in a way that we describe below.

${ }^{10}$ The analysis would be affected in only a minimal way if we restricted interim monitoring to be nonstochastic.

${ }^{11}$ That is, an investment of one unit is required by a bank in order for it to be able to conduct monitoring activity.

${ }^{12}$ This assumption is for simplicity only. In practice it can be thought of as each bank makes loans mostly in a single geographic area or industry, so that returns are correlated across borrowers. Similar assumptions on "one bank-one borrower" are made by John, John, and Saunders (1994); Berlin, John, and Saunders (1996); or Santos (1996a).

${ }^{13}$ This assumption is necessitated by our "one bank-one borrower" specification.

${ }^{14}$ It would also be natural to assume that deposit insurance is publicly provided if the feasibility of insurance provision in all states required potential access to seigniorage revenue.

${ }^{15}$ In effect, a failure to pay $r$ per unit deposited triggers a bankruptcy exactly analogous to 
those in conventional costly state verification models (Diamond 1984, Gale and Hellwig 1985, and Williamson 1986, 1987).

${ }^{16} \mathrm{We}$ allow for the possibility that $\gamma_{F} \geq \gamma_{H}$ holds. For example, since FDIC employees do not have the same claim on the assets of monitored banks as lenders do on borrowers, the FDIC may need to take costly actions to verify that its employees undertake their tasks in an appropriate manner.

${ }^{17}$ Given our assumptions, this is equivalent to a flat rate tax on deposits. However, specifying a tax on lending slightly simplifies the calculations in the text.

${ }^{18}$ In an expanded model we might think of ours as an overlapping generations economy where the government raises resources from the current young to make payments to the current old depositors of failed banks. Our assumption on FDIC behavior is intended to give the analysis this kind of flavor.

${ }^{19} \mathrm{We}$ assume throughout that the lender can commit in advance to liquidate the investment if it is discovered that the borrower has invested in project 2. Thus renegotiation is not a possibility.

${ }^{20}$ All of these "perks" would be consumed by the borrower, since the bank has no ownership position in the firm.

${ }^{21}$ Whether (a.2) holds or not depends, in general, on the equilibrium value of $x_{1}$. We describe its determination below. Note that (a.2) is more likely to hold the larger is $x_{1}$; that is, moral hazard problems appear when rates of interest on loans are sufficiently high.

${ }^{22}$ Assumptions (a.2) and (a.3) imply that $p>0$.

${ }^{23} \mathrm{We}$ emphasize that this is by no means essential to most of our discussion. We show below that credit rationing must obtain if $\alpha>\left(2+q_{2}\right)^{-1}$, and if $\bar{u}$ is sufficiently low.

${ }^{24}$ Of course, in order for borrowers to participate in the loan market, $q_{1}\left\{\hat{z}_{1}-x_{1}+\int_{0}^{x} 1 G(z) d z\right\} \geq$ $\bar{u}$ must hold. If this condition is violated by $\hat{x}_{1}$, then the interest rate must be lowered until borrowers 
are indifferent between obtaining, and not obtaining, credit. Of course, in this case credit is not rationed. We confine our attention to the situation where credit is rationed in the text.

${ }^{25}$ Recall that there is a cost to letting the borrower operate project 2 , since $\hat{z}_{1}>\hat{z}_{2}$.

${ }^{26}$ For the same reasons as before

$$
q_{2}\left\{\hat{z}_{2}-\hat{x}_{2}+\int_{0}^{\hat{x}_{2}} F(z) d z\right\} \geq \bar{u}
$$

must hold for $\hat{x}_{2}$ to be charged. If $\hat{x}_{2}$ violates this condition, the same comments as in footnote 29 apply.

${ }^{27}$ As before all "perks" consumption accrues to the borrower because no one else has an ownership position in the borrower's project.

${ }^{28}$ If the bank lent $q \in\left(q_{2}, q_{1}\right)$ to the borrower, it would be clear to the FDIC that the bank was not attempting to control the moral hazard problem. We assume that this is unacceptable to the FDIC. However, if the bank lends $q_{1}$, the FDIC cannot distinguish between a bank following strategy 1 , and a bank following strategy 3 .

${ }^{29}$ Of course this strategy may not be feasible, since

$$
q_{2} \hat{z}_{2}+\delta\left(q_{1}-q_{2}\right)-\hat{x}_{1}+\int_{0}^{\hat{x}_{1}} F(z) d z \geq \bar{u}
$$

need not hold. The discussion in the text assumes that this condition does hold.

${ }^{30}$ The last statement presumes that (a.2) holds, so that $p\left(\hat{x}_{1}\right)>0$.

${ }^{31}$ There are many reasons why $F\left(\hat{x}_{2}\right)>G\left(\hat{x}_{1}\right)$ might be satisfied. Indeed, assumption (a.1) implies that this condition must be satisfied if $\hat{x}_{2}>\hat{x}_{1}$. The inequality $\hat{x}_{2}>\hat{x}_{1}$ will necessarily hold if $\hat{x}_{2}$ violates (4). Such a violation can result whenever $\delta\left(q_{1}-q_{2}\right) / q_{1}$ is sufficiently large. 
${ }^{32}$ The FDIC's (expected) payments depend on $r$ directly, because each depositor of a failed bank must be paid the difference between $r$ and the per-depositor value of the bank's assets. They depend on $r$ indirectly because $r$ influences the optimal lending strategy of each active bank, and hence the probability that any given bank will fail.

${ }^{33}$ This is truce since the FDIC reinvests all its tax revenue in credit markets.

${ }^{34}$ Of course as we have noted, this is not the only possibility.

${ }^{35}$ In particular, the FDIC must cover the average difference between the promised payment per unit deposited, $r$, and the amount that banks pay out to depositors and the FDIC.

${ }^{36}$ That is, the locus defined by (17) can fail to be increasing at most a single value of $r(1+t)$; the value that renders banks indifferent between strategies 1 and 2 .

${ }^{37}$ If $G(z) / z$ or $F(z) / z$ can be decreasing in $z$ there are clearly several other possible configurations of the locus defined by (17). We do not exhaust the set of possibilities here.

${ }^{38} \mathrm{We}$ do not consider the possibility in this paper that some banks are commercial banks while others are universal banks.

${ }^{39}$ In particular, if the entrepreneur diverts funds without the bank's knowledge, we assume that the entrepreneur does not have to share "perks" consumption with the bank. In effect, then, there is a managerial incentive problem.

${ }^{40}$ Notice that, for any given value of $r$, the probability that a bank following strategy 1 will fail is higher under universal banking than under commercial banking. The same is true of strategies 2 and 3. Of course, it bears emphasis that this argument is purely of a partial equilibrium nature.

${ }^{41}$ Note that $w_{2}$ can, and typically will, be different from $w_{1}$.

${ }^{42} \mathrm{As}$ in Section II, this must be the case if assumption (a.5) is satisfied.

${ }^{43}$ Note that $p\left(w_{1}\right)=1$ holds.

${ }^{44}$ This fact is demonstrated in Appendix C.

${ }^{45}$ That is, if project 2 yields a sufficiently high return relative to $\delta$. 
${ }^{46}$ When there are high and low cost banks, we assume that these conditions are satisfied for both types of banks.

${ }^{47}$ If there are low and high cost banks that are both active in equilibrium, (35) must hold only for high cost banks.

${ }^{48}$ Of course if the values $r$ and $\tau$ satisfying (35) and (36) do not have the property (in conjunction with $t$ ) that banks prefer equity to debt claims, then there is no equilibrium in which all banks operate as universal banks. In this case, if the values $r$ and $\tau$ satisfying (12) and (17) have the property that all banks prefer debt to equity claims, then there is an equilibrium in which all banks operate as commercial banks. Clearly multiple equilibria are possible as well. So are equilibria where banks are indifferent between taking debt and equity positions, and where they take some of each.

${ }^{49}$ As we have seen, this will be the optimal configuration of strategies if interim monitoring costs are relatively high, if $\left(q_{2} / q_{1}\right) \hat{z}_{2}>\delta$, and if $r(1+t)$ is relatively low.

${ }^{50}$ See Akerlof and Romer (1993) for an alternative discussion of how different contractual forms give rise to similar types of problems. They also provide a number of illustrative examples in the context of banking. 


\section{Appendix}

A. Proof of Proposition 1. A commercial bank strictly prefers strategy 2 to strategy 3 iff

$$
\xi\left(\hat{x}_{2}, q_{2} ; \gamma\right)-\Phi_{2}[r(1+t)]>\xi\left[\left(q_{1} / q_{2}\right) \hat{x}_{1}, q_{2} ; \gamma\right]-\Phi_{2}\left[\left(q_{1} / q_{2}\right) r(1+t)\right]
$$

By definition, $\xi\left(\hat{x}_{2}, q_{2} ; \gamma\right) \geq \xi\left[\left(q_{1} / q_{2}\right) \hat{x}_{1}, q_{2} ; \gamma\right]$ must hold. In addition, $\Phi_{2}\left[\left(q_{1} / q_{2}\right) r(1+t)\right]>\Phi_{2}[r(1+t)]$ holds as well, since $\Phi_{2}^{\prime}>0$. This establishes the claim.

B. Proof of Proposition 2. Clearly

$$
\rho^{\prime}\left(w_{1}\right)=q_{1} \hat{z}_{1}-\lambda \tilde{p}^{\prime}\left(w_{1}\right)+q_{1} \int_{0}^{r(1+t) / w_{1}} G(z) d z-q_{1}\left[\frac{r(1+t)}{w_{1}}\right] G\left[\frac{r(1+t)}{w_{1}}\right] \text {. }
$$

Therefore $\rho^{\prime}\left(w_{1}\right)>0$ holds for all $w_{1}$ satisfying (25) if

$$
\left(\gamma / w_{1}\right)+\left(\lambda / w_{1}\right)\left[\tilde{p}\left(w_{1}\right)-w_{1} \tilde{p}^{\prime}\left(w_{1}\right)\right]+\left[\frac{r(1+t)}{w_{1}}\right]\left\{1-G\left[\frac{r(1+t)}{w_{1}}\right]\right\}>0 .
$$

Then obviously a sufficient condition for $\rho^{\prime}\left(w_{1}\right)>0$ to obtain, for all $w_{1}$ obeying (25), is that

$$
\gamma / \lambda \geq w_{1} \tilde{p}^{\prime}\left(w_{1}\right)-\tilde{p}\left(w_{1}\right)
$$

Now the condition (A.4) has the following equivalent representation:

$$
\gamma / \lambda \geq\left[\left(q_{1} \hat{z}_{1}-q_{2} \hat{z}_{2}\right) / q_{2} \hat{z}_{2}\right]+\left[\delta\left(q_{1}-q_{2}\right) / q_{2} \hat{z}_{2}\right]\left(2 w_{1}-1\right) /\left(1-w_{1}\right)^{2} .
$$

Therefore, since the right-hand side of (A.4') is increasing in $w_{1}, \rho^{\prime}\left(w_{1}\right)>0$ must hold for all $w_{1}$ satisfying (22) and (25) if

$$
(\gamma+\lambda) / \lambda \geq\left(q_{1} \hat{z}_{1} / q_{2} \hat{z}_{2}\right)+\left(q_{1} \hat{z}_{1}\right)^{2}\left\{1-\left[2 \delta\left(q_{1}-q_{2}\right) / q_{1} \hat{z}_{1}\right]\right\} / q_{2} \hat{z}_{2} \delta\left(q_{1}-q_{2}\right) .
$$

Rearranging terms in (A.5) gives (a.6). 
C. Proof of Proposition 3. The observations in the text imply that a universal bank prefers strategy 3 to strategy 1 iff

$$
\begin{aligned}
q_{2} \hat{z}_{2}+\delta\left(q_{1}-q_{2}\right)-\bar{u}+q_{2} w_{3} \int_{0}^{\left(q_{1} / q_{2}\right) r(1+t) / w_{3}} F(z) d z \\
>q_{1} \hat{z}_{1}-\delta\left(q_{1}-q_{2}\right)-\lambda+q_{1} w_{1} \int_{0}^{r(1+t) / w_{1}} G(z) d z .
\end{aligned}
$$

We now show that

$$
q_{2} w_{3} \quad \int_{0}^{\left(q_{1} / q_{2}\right) r(1+t) / w_{3}} F(z) d z \geq q_{1} w_{1} \int_{0}^{r(1+t) / w_{1}} G(z) d z
$$

is necessarily satisfied. Then (29) is obviously sufficient for (A.6) to hold.

To establish (A.7), we begin with the following result.

Lemma A1. $q_{1} w_{1} \geq q_{2} w_{3}$ holds.

Proof of Lemma A1. The condition $q_{1} w_{1} \geq q_{2} w_{3}$ is easily shown to be equivalent to

$$
\hat{z}_{2}\left(\hat{z}_{1}-\delta\right)\left(q_{1}-q_{2}\right)+\left[\delta \hat{z}_{1}\left(q_{1}-q_{2}\right)^{2} / q_{2}\right] \geq\left[\delta^{2}\left(q_{1}-q_{2}\right)^{2} / q_{2}\right]-\hat{z}_{1} \bar{u}
$$

But (A.8) must hold since $\hat{z}_{1}>\delta$.

We now show that (A.7) obtains. To do so, note that (A.7) is equivalent to

$$
q_{1} w_{1}\left\{\left(\frac{q_{2} w_{3}}{q_{1} w_{1}}\right)^{\left(q_{1} w_{1} / q_{2} w_{3}\right) r(1+t) / w_{1}} F(z) d z-\int_{0}^{r(1+t) / w_{1}} G(z) d z\right\} \geq 0 .
$$

We now make use of the following result. 
Lemma A2. Define the function $H(s)$ by

$$
H(s) \equiv s^{-1} \int_{0}^{s r(1+t) / w_{1}} F(z) d z-\int_{0}^{r(1+t) / w_{1}} G(z) d z
$$

Then $H(s) \geq 0$, for all $s \geq 1$.

Together lemmas A1 and A2 imply that $H\left[\left(q_{2} w_{3}\right) /\left(q_{1} w_{1}\right)\right] \geq 0$, implying that (A.7) is satisfied. Our proof is therefore completed by the following:

Proof of Lemma 2. Assumption (a.1) implies that $H(1) \geq 0$. In addition,

$$
\begin{aligned}
H^{\prime}(s) & =s^{-1}\left[\frac{r(1+t)}{w_{1}}\right] F\left[\frac{s r(1+t)}{w_{1}}\right]-s^{-2} \int_{0}^{s r(1+t) / w_{1}} F(z) d z \\
& >s^{-1}\left[\frac{r(1+t)}{w_{1}}\right] F\left[\frac{s r(1+t)}{w_{1}}\right]-s^{-1}\left[\frac{r(1+t)}{w_{1}}\right] F\left[\frac{s r(1+t)}{w_{1}}\right]=0 .
\end{aligned}
$$

It is then immediate that $H(s) \geq 0 \forall s \geq 1$.

D. Proof of Proposition 4. A universal bank prefers strategy 3 to strategy 2 iff

$$
[r(1+t)-\delta]\left(q_{1}-q_{2}\right) / q_{2}<\left(w_{3}-w_{2}\right) \int_{0}^{\left(q_{1} / q_{2}\right) r(1+t) / w_{3}} F(z) d z+w_{2} \int_{r(1+t) / w_{2}}^{\left(q_{1} w_{2} / q_{2} w_{3}\right) r(1+t) / w_{2}} F(z) d z
$$

is satisfied. Moreover,

$$
w_{3}-w_{2}=\bar{u} \delta\left(q_{1}-q_{2}\right) / q_{2} \hat{z}_{2}\left[q_{2} \hat{z}_{2}+\delta\left(q_{1}-q_{2}\right)\right]>0 .
$$

We now prove part (a) of the proposition.

(a) Using the expressions stated in the text for $w_{2}$ and $w_{3}$, it is straightforward to verify that $q_{1} w_{2}>q_{2} w_{3}$ holds iff

$$
q_{1}-q_{2}>\bar{u}\left(q_{1}-q_{2}\right)\left(q_{2} \hat{z}_{2}+\delta q_{1}\right) /\left(q_{2} \hat{z}_{2}\right)\left[q_{2} \hat{z}_{2}+\delta\left(q_{1}-q_{2}\right)\right]
$$


Rearranging terms in (A.11) gives (32) in the text.

(b) If (32) holds, then satisfaction of (33) implies the satisfaction of (A.10). This establishes part (b) of the proposition.

(c) When (32) holds, a sufficient condition for (33) to be satisfied is that

$$
F\left[\frac{r(1+t)}{w_{2}}\right]\left[\left(q_{1} w_{2} / q_{2} w_{3}\right)-1\right] \geq\left(q_{1}-q_{2}\right)[r(1+t)-\delta] / q_{2} r(1+t) .
$$

Moreover,

$$
\left(q_{1} w_{2} / q_{2} w_{3}\right)-1>\left(q_{1} / q_{2}\right) w_{2}-1=\left[\left(q_{1}-q_{2}\right) q_{2} \hat{z}_{2}-q_{1} \bar{u}\right] /\left(q_{2}\right)^{2} \hat{z}_{2} .
$$

It follows that (A.12) must be satisfied if

$$
F\left[\frac{r(1+t)}{w_{2}}\right]\left\{q_{2} \hat{z}_{2}-\left[q_{1} \bar{u} /\left(q_{1}-q_{2}\right)\right]\right\}>[r(1+t)-\delta] q_{2} \hat{z}_{2} / r(1+t) .
$$

Finally, (a.7) implies that $q_{2} \hat{z}_{2}-\left[q_{1} \bar{u} /\left(q_{1}-q_{2}\right)\right]<q_{2} \hat{z}_{2}-q_{1} \delta$. It follows that (34) implies the satisfaction of (A.12), completing the proof.

\section{E. Proof of Proposition 5.}

In order to prove proposition 5, we begin by noting that equation (38) has the following equivalent representation:

$$
\begin{aligned}
& q_{2} \hat{z}_{2}-q_{2}\left(\hat{x}_{2}-\int_{0}^{\hat{x}_{2}} F(z) d z\right)-\bar{u}+[\delta-r(1+t)]\left(q_{1}-q_{2}\right) \\
& +q_{2} w_{3} \int_{0}^{\left(q_{1} / q_{2}\right) r(1+t) / w_{3}} F(z) d z-q_{2} \int_{0}^{r(1+t)} F(z) d z>\gamma\left[1-F\left(\hat{x}_{2}\right)\right] .
\end{aligned}
$$

We now show that (39) implies the satisfaction of (A.14), and hence of (38). To do so we note that 


$$
q_{2} w_{3} \int_{0}^{\left(q_{1} / q_{2}\right) r(1+t) / w_{3}} F(z) d z-q_{2} \int_{0}^{r(1+t)} F(z) d z>\left(q_{1}-q_{2}\right) r(1+t) F[r(1+t)]
$$

and (39) necessarily imply the satisfaction of (A.14), since

$$
q_{2} \hat{z}_{2}-q_{2}\left(\hat{x}_{2}-\int_{0}^{\hat{x}_{2}} F(z) d z\right) \geq \bar{u}
$$

holds. Thus, to prove the proposition, we need only establish that (A.15) obtains. We begin with the following lemma.

Lemma A3. Define the function $D(s)$ by

$$
D(s) \equiv s q_{2} \int_{0}^{\left(q_{1} / q_{2}\right) r(1+t) / s} F(z) d z
$$

Then

$$
D(s) \geq q_{2} \int_{0}^{\left(q_{1} / q_{2}\right) r(1+t)} F(z) d z, \forall s \leq 1 .
$$

Proof of Lemma A3. Clearly,

$$
D(1)=q_{2} \int_{0}^{\left(q_{1} / q_{2}\right) r(1+t)} F(z) d z
$$

holds. Moreover, 


$$
\begin{aligned}
D^{\prime}(s)=q_{2} & \int_{0}^{\left(q_{1} / q_{2}\right) r(1+t) / s} F(z) d z-q_{1}\left[\frac{r(1+t)}{s}\right] F\left[\left(\frac{q_{1}}{q_{2}}\right) \frac{r(1+t)}{s}\right] \\
& <q_{2}\left(q_{1} / q_{2}\right)\left[\frac{r(1+t)}{s}\right] F\left[\left(\frac{q_{1}}{q_{2}}\right) \frac{r(1+t)}{s}\right]-q_{1}\left[\frac{r(1+t)}{s}\right] F\left[\left(\frac{q_{1}}{q_{2}}\right) \frac{r(1+t)}{s}\right]=0 .
\end{aligned}
$$

Then $D(s) \geq D(1)$, for all $s \leq 1$, establishing the claim.

Lemma A3 implies that

$$
\begin{aligned}
q_{2} w_{3} & \int_{0}^{\left(q_{1} / q_{2}\right) r(1+t) / w_{3}} F(z) d z-q_{2} \int_{0}^{r(1+t)} F(z) d z>q_{2} \int_{0}^{\left(q_{1} / q_{2}\right) r(1+t)} F(z) d z-q_{2} \int_{0}^{r(1+t)} F(z) d z \\
& =q_{2} \int_{r(1+t)}^{\left(q_{1} / q_{2}\right) r(1+t)} F(z) d z
\end{aligned}
$$

is satisfied. Moreover,

$$
q_{2} \int_{r(1+t)}^{\left(q_{1} / q_{2}\right) r(1+t)} F(z) d z \geq F[r(1+t)] r(1+t)\left(q_{1}-q_{2}\right)
$$

But (A.16) and (A.17) together yield (A.15), and therefore (39) implies the satisfaction of (38). 


\section{References}

Akerlof, George A., and Paul M. Romer. "Looting: The Economic Underworld of Bankruptcy for Profit." Brookings Papers on Economic Activity, 1-60, 1993.

Allen, Franklin, and Douglas Gale. “A Welfare Comparison of Intermediaries and Financial Markets in Germany and the U.S.” European Economic Review 39 (1995), 179-209.

Berlin, Mitchell, Kose John, and Anthony Saunders. "Bank Equity Stakes in Borrowing Firms and Financial Distress.” Review of Financial Studies 9 (1996), 889-919.

Boot, Arnoud, and Anjan V. Thakor. "Financial System Architecture." Working Paper, Indiana University, 1994.

. "Banking Scope, Financial Innovation, and the Evolution of the Financial System." Review of Financial Studies, forthcoming.

Boyd, John H., and Bruce D. Smith. "How Good Are Standard Debt Contracts? Stochastic Versus Nonstochastic Monitoring in a Costly State Verification Environment.” Journal of Business 67 (1994), 539-61.

Corrigan, Gerald. Annual Report. Federal Reserve Bank of Minneapolis, 1983. "The Separation of Banking From Commerce." Statement before the U.S. Senate Committee on Banking, Housing, and Urban Affairs, July 18, 1987.

Dewatripont, Mathias, and Jean Tirole. The Prudential Regulation of Banks. Cambridge, Mass.: MIT Press, 1994.

Diamond, Douglas. "Financial Intermediation and Delegated Monitoring." Review of Economic Studies 51 (1984), 393-414.

Gale, Douglas, and Martin Hellwig. "Incentive-Compatible Debt Contracts: The One Period Problem." Review of Economic Studies 52 (1985), 647-63. 
Gertler, Mark, and R. Glenn Hubbard. "Financial Factors in Business Fluctuations." Financial Market Volatility. Federal Reserve Bank of Kansas City, 1988.

Gertler, Mark, and Kenneth Rogoff. "North-South Lending and Endogenous Domestic Capital Market Inefficiencies.” Journal of Monetary Economics 26 (1990), 245-66.

Gorton, Gary, and Joseph G. Haubrich. "Bank Deregulation, Credit Markets, and the Control of Capital.” Carnegie-Rochester Conference Series on Public Policy 26 (1987), 289-334.

Gorton, Gary, and Frank A. Schmid. "Universal Banking and the Performance of German Firms." Working Paper, University of Pennsylvania, 1996.

Hauswald, Robert B. H. "Financial Contracting, Reorganization and Mixed Finance: A Theory of Banking Systems.” Manuscript, University of Maryland, 1996.

James, Christopher. "When Do Banks Take Equity? An Analysis of Bank Loan Restructuring and the Role of Public Debt.” Working Paper, University of Florida, 1993.

John, Kose, T. A. John, and Anthony Saunders. "Universal Bank and Firm Risk Taking.” Journal of Banking and Finance 18 (1994), 307-23.

Kareken, John H., and Neil Wallace. "Deposit Insurance and Bank Regulation: A Partial Equilibrium Exposition.” Journal of Business 51 (July 1978), 413-38.

Kroszner, Randall S., and Raghuran G. Rajan. "Is the Glass-Steagall Act Justified? A Study of the U.S. Experience With Universal Banking Before 1933." American Economic Review 84 (1994), 810-32.

Merton, Robert C. “An Analytical Derivation of the Cost of Deposit Insurance and Loan Guarantees: An Application of Modern Option Pricing Theory." Journal of Business and Finance 1 (June 1977), 3-11.

Pozdena, Randall J. "Why Banks Need Commerce Powers.” Federal Reserve Bank of San Francisco Economic Review (1991), 18-30. 
Santos, Joao. "Bank Capital and Equity Investment Regulations." Working Paper, Federal Reserve Bank of Cleveland, 1996a.

. "Commercial Banks in the Securities Business: A Review." Working Paper, Federal Reserve Bank of Cleveland, 1996b.

Saunders, Anthony. "Banking and Commerce: An Overview of Public Policy Issues." Journal of Banking and Finance 18 (1994), 231-54.

. Financial Institutions Management: A Modern Perspective. New York: Irwin, 1997.

Saunders, Anthony, and Ingo Walter. Universal Banking in the United States: What Could We Gain? What Could We Lose? New York: Oxford University Press, 1994.

Townsend, Robert M. "Optimal Contracts and Competitive Markets With Costly State Verification." Journal of Economic Theory 21 (1979), 265-93.

Williamson, Stephen D. "Costly Monitoring, Financial Intermediation and Equilibrium Credit Rationing." Journal of Monetary Economics 18 (1986), 159-79.

. "Costly Monitoring, Loan Contracts, and Equilibrium Credit Rationing." Quarterly Journal of Economics 102 (1987), 135-45. 
FIGURE 1

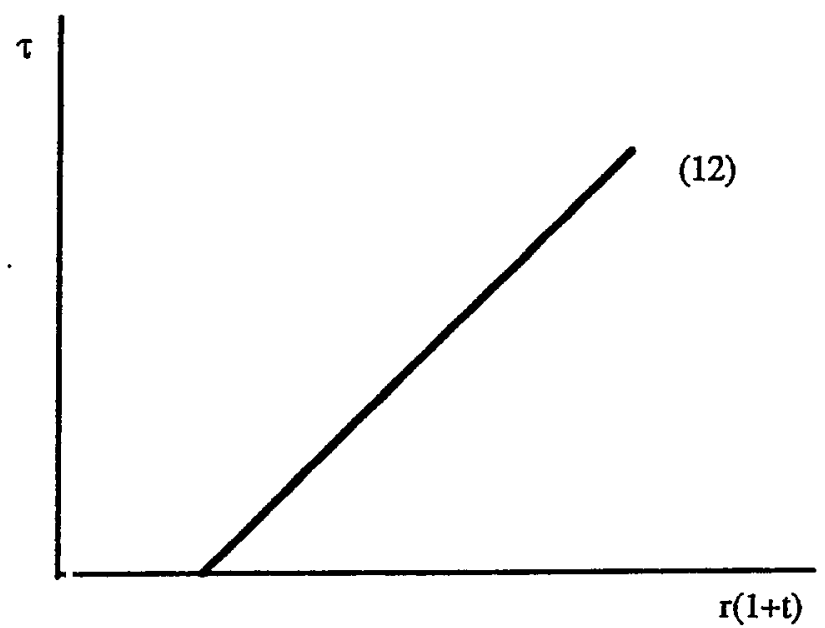

A bank earns "normal" profits if (12) holds. 
FIGURE 2.a

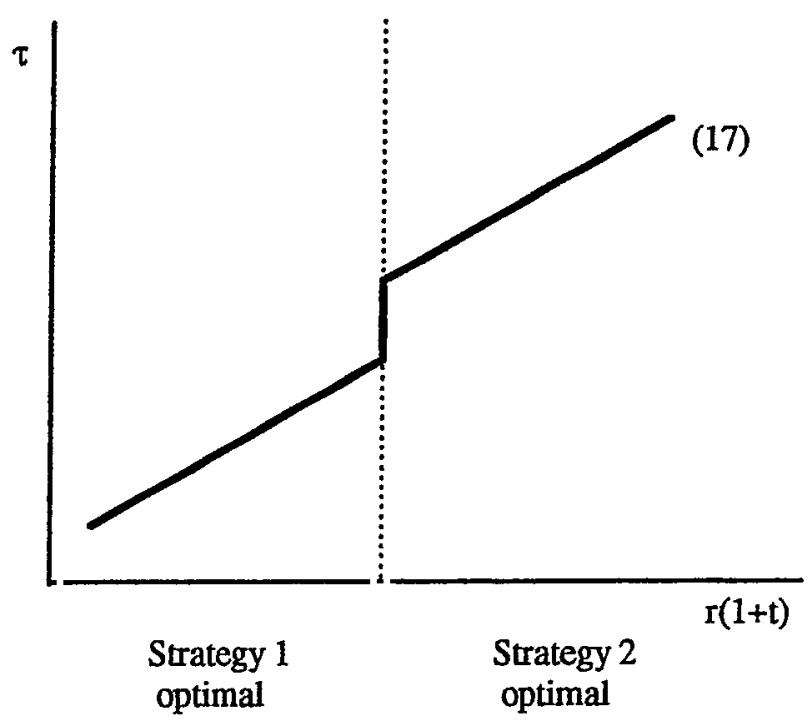

FIGURE 2.b

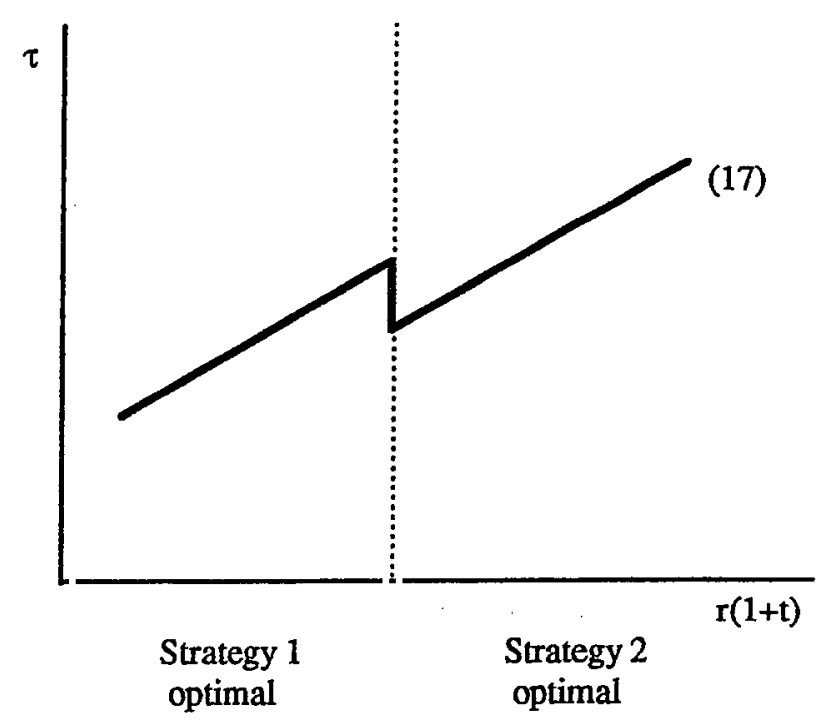


FIGURE 3.a

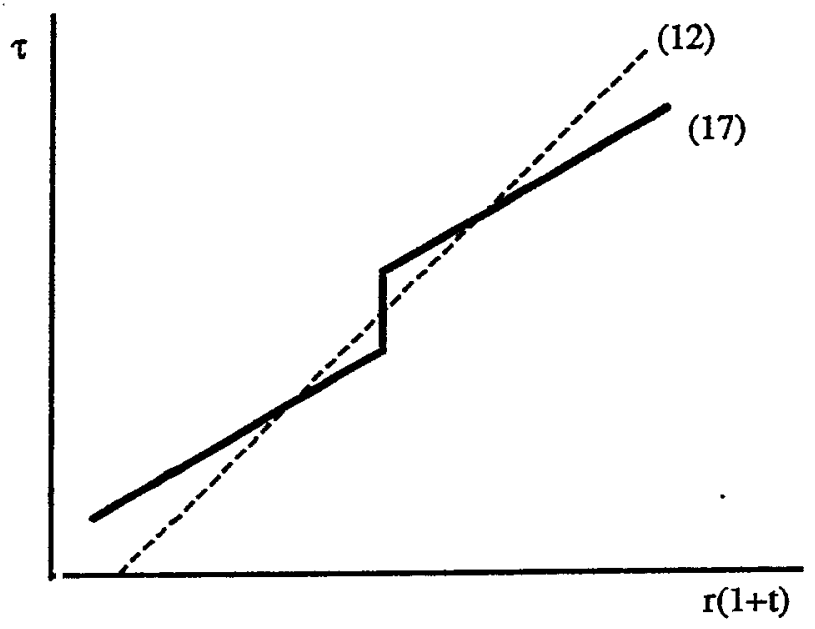

FIGURE 3.b

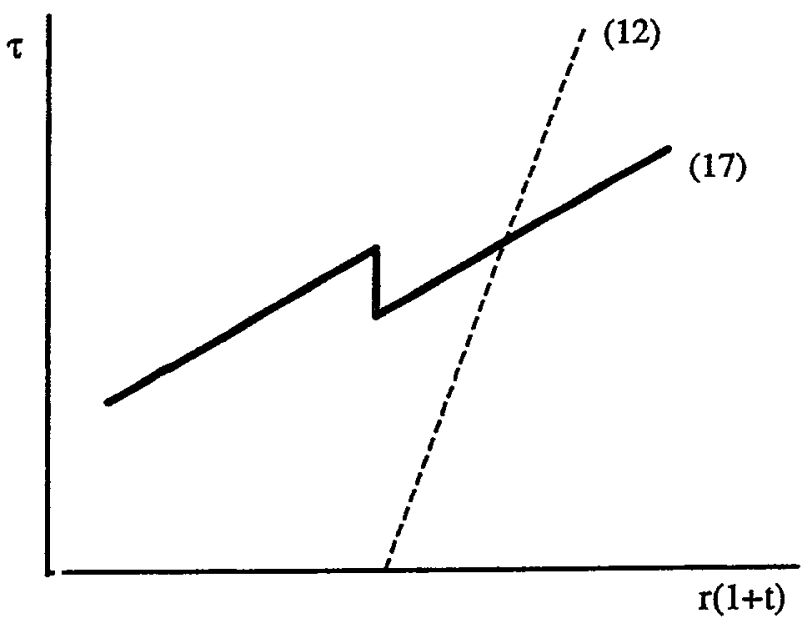


FIGURE 4

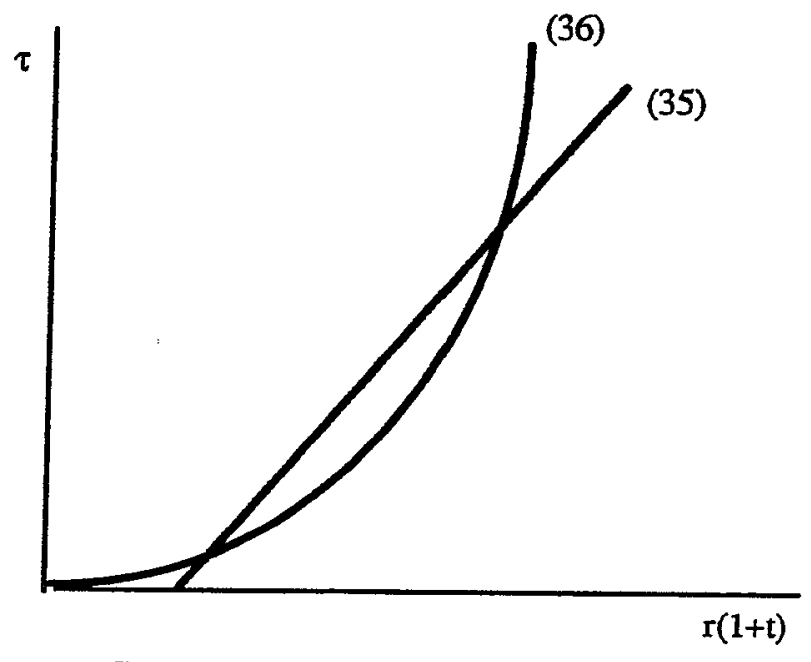

General equilibrium: universal banking 